\title{
Mooring System Fatigue Analysis for a Semi-Submersible
}

Xutian Xue ${ }^{1}$, Nian-Zhong Chen ${ }^{2 *, 1}$, Yongyan $W^{3}$, Yeping Xiong ${ }^{4}$, Yunhua Guo ${ }^{1,5}$

${ }^{1}$ School of Engineering, Newcastle University, Newcastle upon Tyne, United Kingdom, NE1 7RU

${ }^{2}$ College of Shipbuilding Engineering, Harbin Engineering University, Harbin, China, 15001

${ }^{3}$ Aker Solutions Inc., 3010 Briarpark Dr., Suite 500, Houston, TX 77042, USA

${ }^{4}$ Faculty of Engineering and the Environment, University of Southampton, Southampton, United Kingdom, SO17 1BJ

${ }^{5}$ School of Energy and Power Engineering, Wuhan University of Technology, Wuhan, China, 430063

*Correspondence address:

Nian-Zhong Chen (Ph.D.)

Professor in Subsea Engineering,

College of Shipbuilding Engineering,

Harbin Engineering University,

145 Nantong Street, Nangang District,

Harbin, Heilongjiang province, China, 150001

Tel: +86 13206553227

Email: nzchen2008@gmail.com

\section{Abstract}

T-N curves, S-N curves, and fracture mechanics (FM) based mooring system fatigue analyses for a semisubmersible are presented. Stress ranges are calculated based on the tension ranges of mooring lines subjected to the combined loading process induced by the motions of wave frequency (WF) and low frequency (LF). A comparison between T-N curves, S-N curves, and FM based mooring fatigue analyses for the semi-submersible is made and the results show that the fatigue lives predicted by the three approaches 
are in general comparable if the safety factors suggested by API and DNVGL are considered in the T-N and S-N curves based approaches. In addition, the crown section of a mooring chain is prone to fatigue damage compared to bend and weld sections without considering the SCF. A parametric study to investigate the impact of initial crack shape, critical crack depth, and initial crack sizes on fatigue life of a mooring chain is also conducted and the results show that fatigue life of a mooring chain predicted by the FM approach is generally sensitive to initial crack shape and initial crack sizes, however, it is relatively insensitive to the critical crack depth.

Keywords: Semi-submersible, fatigue assessment, T-N curves, S-N Curves, fracture mechanics (FM) 


\section{Introduction}

Safety is crucially important for offshore floating structures. However, over the past few decades, mooring accidents of permanent floating structures occurred at a high rate. Ma et al. (2013) reported that 23 mooring failures happened from 2001 to 2011, in which three failures were due to fatigue. Kvitrud (2014) reviewed 15 mooring failures in Norwegian sea during 2010 to 2013 and one third of them were fatigue failures. These accident reports clearly indicate fatigue failure has become one of critical failure modes of a mooring system. There is thus a need to develop rational methods for fatigue assessment of a mooring system during the design phase.

The attempt to understand the fatigue behaviour of offshore mooring chains was done by de Laval (1971) who conducted a series of fatigue tests on mooring chains. Van Helvoirt (1982) performed experimental studies to investigate the static strength and the fatigue strength of 3 -inch studlink chains and of three types of 3-inch connecting links (Kenter, Baldt, and D shackle) in high-cycle fatigue range in an artificial sea-water environment. Based on the results from a four-year DNV project on mooring lines, S-N curves for mooring chain links were summarized by Lereim (1985). A series of experiments for the mooring lines of offshore floating structures were launched by API (1993) and the T-N curves for mooring line fatigue designs were released.

Afterwards, considerable work was conducted on mooring system fatigue analysis using the T-N or SN curves based approaches. Lassen and Syvertsen (1997) applied T-N curves to predict the fatigue damage of mooring lines. Horde and Moan (1997) carried out mooring fatigue analysis accounting for the combination of low frequency and wave frequency motions. Gao and Moan (2007) performed a frequencydomain analysis for bimodal nonGaussian fatigue damage prediction of mooring lines based on a simplified mechanical model and S-N curves. Olagnon and Guédé (2008) proposed approximate formulae for predicting mooring line fatigue damage with a combined spectrum of one or several narrow-band low frequency loads and a higher frequency load based on S-N curves. Xu et al. (2013) performed fatigue analysis for a net cage mooring system using both the spectrum analysis method and the rainflow counting method. Wu et al. (2015) conducted mooring fatigue analyses for semi-submersibles using the frequencydomain analysis based on T-N curves where low frequency and wave frequency loading and their 
combination are considered.

Recently, there are some attempts of the application of fracture mechanics for mooring system fatigue analysis. Mathisen and Larsen (2004) applied the linear elastic fracture mechanics to predict the mooring chain fatigue life and initial cracks are assumed to grow from the surface of a chain link with a semi-elliptical shape. Lassen et al. (2005) conducted a series of experiments to investigate the crack growth behaviour of high strength mooring chains in a corrosive environment and S-N curves based approaches and the linear elastic fracture mechanics analysis were performed to compare with experimental results. Lardier et al. (2008) performed both S-N curves and the linear fracture mechanics based fatigue analysis for mooring lines considering corrosion effects and correlation between chain links. Palin-Luc et al. (2010) and Pérez-Mora et al. (2015) conducted a number of experiments on R5 grade steel to investigate the effect of corrosion on very high cycle fatigue strength. A fracture mechanics analysis in which the stress intensity factor is estimated with hemispherical surface defects combined Paris-Hertzberg-Mc Clintock crack growth rate model was performed to compare with experimental results.

As seen from the above literature review, a mooring fatigue analysis is traditionally conducted based on T-N curves or S-N curves and there is relatively less work done on fracture mechanics analysis. This paper is to perform T-N curves, S-N curves, and fracture mechanics based mooring fatigue analyses for a semi-submersible installed in Gulf of Mexico (GoM). Stress ranges are calculated based on the tension ranges of mooring lines subjected to the combined loading process induced by the motions of wave frequency (WF) and low frequency (LF). For fracture mechanics analysis, the chain links of mooring lines are treated as round bars and initial surface cracks are assumed to propagate at the surface of chain links. The stress intensity factor ranges are then calculated based on a finite element analysis. A comparison between T-N curves, S-N curves, and fracture mechanics based mooring fatigue analyses for the semi-submersible is made and a parametric study to investigate the impact of initial crack shape, initial crack sizes, and critical crack depth on fatigue lives of mooring lines is also conducted.

\section{Semi-submersible and mooring systems}

A four-column ring pontoon semisubmersible with 16 mooring lines operated at the Gulf of Mexico 
is considered in this paper. Two types of mooring systems, namely, catenary and taut mooring systems with four cases are designed for the semisubmersible.

\subsection{Semi-submersible Hull}

The semi-submersible hull comprises a ring pontoon and four vertical, surface piercing columns. The platform structures under main deck are symmetric in both east-west and south-north directions. The geometry of platform hull is shown in Figs. 1 and 2 and the principal dimensions of platform hull are listed in Table 1.

\subsection{Mooring systems}

The semi-submersible is spread moored with $16(4 \times 4)$ homogenous material mooring lines emanating from four corner columns. The mooring system is symmetric in both east-west and south-north directions. Mooring line 1 is 37.5 degree clockwise from platform north and each two neighbouring mooring lines in the same cluster lay with 5 degree separation. The detailed layout of mooring lines with numbering is shown in Fig. 2.

Four mooring systems (A, B, C and D) are designed for this semi-submersible. Cases $A$ and $B$ are taut mooring systems. Cases $C$ and $D$ are catenary mooring systems. For each mooring system, the operating water depth is $6000 \mathrm{ft}$ and the design life is 25 years. Each mooring line consists of a 6 -inch R4 grade studless bottom chain, a $267 \mathrm{~mm}$ polyester rope, and a $150 \mathrm{~m}$ long 6 -inch R4 grade studless top chain. The length of bottom chain is $210 \mathrm{~m}$ and the top chain is $150 \mathrm{~m}$ long. The polyester ropes are $2600 \mathrm{~m}$ long with four segments. The wear and corrosion rate of mooring chains is assumed be $0.5 \mathrm{~mm}$ per year. The normal and longitudinal drag coefficients are set as $(2.4,1.15)$ for chains and $(1.2,0.1)$ for fibre ropes, respectively. The friction coefficient between the bottom line and seafloor is assumed to be 1.0 for catenary mooring systems. The connecting links jointing each mooring line segment are considered in Cases $A$ and $C$ but not accounted for in Cases B and D.

The details of the four mooring systems are summarized in Tables 2 and 3. 


\subsection{Environmental conditions}

The semi-submersible is assumed to be installed and operated at the central of Gulf of Mexico. The typical wave, wind and current conditions of the central of Gulf of Mexico have been taken into account in the mooring fatigue analysis (API RP 2MET, 2014). Compared to a ship-shaped vessel, the semi-submersible is relatively insensitive to the directions of wave, wind and current. The spread mooring system is designed to hold the semi-submersibles at the operating location. The sea states of Gulf of Mexico considering wave, wind and current in collinear directions are listed in Table 4 (Wu et al., 2015).

\section{Mooring line tension}

A mooring system is a set of mooring lines to hold a structure against environmental forces. The function of the mooring line tension $T$ normally can be written as

$$
T=T_{M}+T_{D}
$$

where $T_{M}$ is the mean tension due to pretension and mean environmental loads, $T_{D}$ is the dynamic tension of the mooring line due to environmental loads, which is usually taken as a combination of low frequency (LF) tension and wave frequency (WF) tension.

In this section, methods to calculate LF and WF tension of a single 2D catenary mooring system of a vessel with slow motion is introduced and also how to combine LF and WF tension is described.

\subsection{Quasi-static low frequency (LF) tension along mooring line}

A quasi-static analysis method is used for evaluating the LF tension of a catenary mooring system in which the low frequency tension is taken into account by vessel offsetting induced by the second order waves and wind dynamics. In this approach, dynamic effects associated with mass, damping and fluid acceleration on the mooring lines are neglected.

As shown in Fig.3, a 2D multi-material mooring line with segment numberings on a vessel with slow motion is considered. The origin of the reference coordinate system $(x, z)$ is located at the touch down point (TDP). $X$ is the horizontal distance from TDP to the fairlead, $Z$ is the vertical distance from the seabed 
to the fairlead. The static equations for mooring system can be written as

$$
\begin{aligned}
& T_{L}=\sqrt{T_{H}^{2}+\left(\sum w_{i} l_{i}\right)^{2}} \\
& X=\sum x_{i} \\
& Z=\sum z_{i}
\end{aligned}
$$

where $T_{L}$ is summation of the pretension and mooring line tension at the fairlead induced by LF motions, $T_{H}$ the horizontal tension force at fairlead, $i$ the mooring component number, $w_{i}$ the unit mooring line wet weight of each mooring component, $l_{i}$ the suspended length of each mooring component. $x_{i}$ and $Z_{i}$ denote the projected horizontal length and vertical depth of each suspended mooring component, respectively.

If this $2 \mathrm{D}$ multi-material mooring line is in a catenary mooring system, $x_{i}$ and $z_{i}$ can be given as

$$
\begin{aligned}
x_{1}= & \frac{T_{H}}{w_{1}} \sinh ^{-1}\left(\frac{w_{1} l_{1}}{T_{H}}\right) \\
z_{1}= & \frac{T_{H}}{w_{1}}\left[\cosh \left(\frac{w_{1} x_{1}}{T_{H}}\right)-1\right] \\
x_{2}= & \frac{T_{H}}{w_{2}}\left[\sinh ^{-1}\left(\frac{w_{2} l_{2}+w_{1} l_{1}}{T_{H}}\right)-\sinh ^{-1}\left(\frac{w_{1} l_{1}}{T_{H}}\right)\right] \\
z_{2}= & \frac{T_{H}}{w_{2}}\left[\cosh \left(\frac{w_{2} x_{2}}{T_{H}}+\sinh ^{-1}\left(\frac{w_{1} l_{1}}{T_{H}}\right)\right)-\cosh \left(\sinh ^{-1}\left(\frac{w_{1} l_{1}}{T_{H}}\right)\right)\right] \\
x_{3}= & \frac{T_{H}}{w_{3}}\left[\sinh ^{-1}\left(\frac{w_{3} l_{3}+w_{2} l_{2}+w_{1} l_{1}}{T_{H}}\right)-\sinh ^{-1}\left(\frac{w_{2} l_{2}+w_{1} l_{1}}{T_{H}}\right)\right] \\
z_{3}= & \frac{T_{H}}{w_{3}}\left[\cosh \left(\frac{w_{3} x_{3}}{T_{H}}+\sinh ^{-1}\left(\frac{w_{2} l_{2}+w_{1} l_{1}}{T_{H}}\right)\right)-\cosh \left(\sinh ^{-1}\left(\frac{w_{2} l_{2}+w_{1} l_{1}}{T_{H}}\right)\right)\right]
\end{aligned}
$$

If this $2 \mathrm{D}$ multi-material mooring line is in a taut mooring system, the equation for $x_{i}$ and $z_{i}$ can be expressed as

$$
\begin{aligned}
& x_{1}=\frac{T_{H}}{w_{1}}\left[\sinh ^{-1}\left(\frac{w_{1} l_{1}}{T_{H}}+\tan \theta_{1}\right)-\sinh ^{-1}\left(\tan \theta_{1}\right)\right] \\
& z_{1}=\frac{T_{H}}{w_{1}}\left[\cosh \left(\frac{w_{1} x_{1}}{T_{H}}+\sinh ^{-1}\left(\tan \theta_{1}\right)\right)-\cosh \left(\sinh ^{-1}\left(\tan \theta_{1}\right)\right)\right] \\
& x_{2}=\frac{T_{H}}{w_{2}}\left[\sinh ^{-1}\left(\frac{w_{2} l_{2}+w_{1} l_{1}}{T_{H}}+\tan \theta_{1}\right)-\sinh ^{-1}\left(\frac{w_{1} l_{1}}{T_{H}}+\tan \theta_{1}\right)\right]
\end{aligned}
$$




$$
\begin{aligned}
& z_{2}=\frac{T_{H}}{w_{2}}\left[\cosh \left(\frac{w_{2} x_{2}}{T_{H}}+\sinh ^{-1}\left(\frac{w_{1} l_{1}}{T_{H}}+\tan \theta_{1}\right)\right)-\cosh \left(\sinh ^{-1}\left(\frac{w_{1} l_{1}}{T_{H}}+\tan \theta_{1}\right)\right)\right] \\
& x_{3}=\frac{T_{H}}{w_{3}}\left[\sinh ^{-1}\left(\frac{w_{3} l_{3}+w_{2} l_{2}+w_{1} l_{1}}{T_{H}}+\tan \theta_{1}\right)-\sinh ^{-1}\left(\frac{w_{2} l_{2}+w_{1} l_{1}}{T_{H}}+\tan \theta_{1}\right)\right] \\
& z_{3}=\frac{T_{H}}{w_{3}}\left[\cosh \left(\frac{w_{3} x_{3}}{T_{H}}+\sinh ^{-1}\left(\frac{w_{2} l_{2}+w_{1} l_{1}}{T_{H}}+\tan \theta_{1}\right)\right)-\cosh \left(\sinh ^{-1}\left(\frac{w_{2} l_{2}+w_{1} l_{1}}{T_{H}}+\tan \theta_{1}\right)\right)\right]
\end{aligned}
$$

where $\theta_{1}$ is the mooring line angle from horizontal at anchor point.

\subsection{Damping along mooring line}

The drag coefficients, both normal and tangential to a mooring line, are required when a dynamic analysis is carried out. Let $\Psi(l)$ be the displacement which is normal to the mooring line and $\Phi(l)$ the displacement along the mooring line. The damping forces are given as

$$
\begin{aligned}
& F_{\Psi}=\frac{1}{2} \rho C_{d n} D \frac{\delta[\Psi(l)]}{\delta t}\left|\frac{\delta[\Psi(l)]}{\delta t}\right| \\
& F_{\Phi}=\frac{1}{2} \rho C_{d l} D \frac{\delta[\Phi(l)]}{\delta t}\left|\frac{\delta[\Phi(l)]}{\delta t}\right|
\end{aligned}
$$

where $\rho$ is water density, $C_{d n}$ and $C_{d l}$ are drag coefficients in normal and longitudinal directions, respectively.

For low frequency slow-drift motion, $F_{\Psi}$ and $F_{\Phi}$ can be expressed as (Garza Rios et al., 1997)

$$
\begin{aligned}
& F_{\Psi}=\frac{1}{2 w^{2}} \rho C_{d n} D\left(g_{\Psi}\left(\theta_{0}, \theta\right) \times\left|g_{\Psi}\left(\theta_{0}, \theta\right)\right|\right) \frac{\delta[\Psi(l)]}{\delta t}\left|\frac{\delta[\Psi(l)]}{\delta t}\right| \\
& F_{\Phi}=\frac{1}{2 w^{2}} \rho C_{d l} D\left(g_{\Phi}\left(\theta_{0}, \theta\right) \times\left|g_{\Phi}\left(\theta_{0}, \theta\right)\right|\right) \frac{\delta[\Phi(l)]}{\delta t}\left|\frac{\delta[\Phi(l)]}{\delta t}\right|
\end{aligned}
$$

where

$$
\begin{aligned}
& g_{\Psi}\left(\theta_{0}, \theta\right)=\sin \theta \tan \frac{\theta_{0}}{2}+1-\cos \theta-\sin \theta \operatorname{arsinh}(\tan \theta) \\
& g_{\Phi}\left(\theta_{0}, \theta\right)=(1-\cos \theta) \tan \frac{\theta_{0}}{2}-\sin \theta+\cos \theta \operatorname{arsinh}(\tan \theta)
\end{aligned}
$$

where $\theta_{0}$ is the mooring line angle from horizontal at fairlead and $\theta$ the mooring line angle from horizontal in suspended section.

Considering the value of $g_{\Psi}\left(\theta_{0}, \theta\right)$ and $g_{\Phi}\left(\theta_{0}, \theta\right)$, it can be found that both normal and longitudinal damping are almost zero near touch down point (TDP) because $\theta$ is close to zero degree. In addition, the maximum normal damping force occurs at the middle section of suspended mooring line and longitudinal 
damping increases from the TDP towards the fairlead.

\subsection{Dynamic analysis for wave frequency (WF) tension}

The variation in mooring tension caused by wave frequency motions is calculated by a dynamic method. In this analysis, the mooring cable is modelled as a dynamic system (Barltrop, 1998)

$$
M_{a} \frac{d^{2} x}{d t^{2}}+C \frac{d x}{d t}+K_{s} x=F_{\text {static }}+F_{W F}+T_{W}
$$

where, $x$ is the displacement vector from mean position. $M_{a}, C$ and $K_{s}$ are matrices of mass, damping and stiffness, respectively. $F_{\text {static }}$ is the static load, $F_{W F}$ is the first order wave loads which are imposed at wave frequency, $T_{W}$ is the tension from the mooring system, which is considered as the summation of the pretension and mooring line tension induced by the first order wave loads.

For the mooring fatigue analysis presented herein, the WF mooring line is computed in terms of the response amplitude operators (RAOs) achieved from a frequency-domain analysis. RAOs of the tension and displacement of a mooring line in the direction of line tangent at its fairlead for the four designed mooring systems are shown in Figs. 4 and 5, respectively.

\subsection{Wave and low frequency tension combination}

In the present paper, as recommended by API RP 2SK (2008), the wave frequency (WF) and low frequency (LF) load processes are regarded as two independent narrow-banded random Gaussian processes and the combination spectrum of the two processes, namely the dynamic tension $T_{D}$, is also assumed to be a narrow-banded process. The fatigue damage estimated by such a method generally tends to be conservative compared to the rainflow counting method (Wirsching and Light, 1980).

For a narrow-banded Gaussian process, peaks of the process, $T_{p}$, follows a Rayleigh distribution and the probability density function of $T_{p}$ can be given by

$$
f\left(T_{p}\right)=\frac{T_{p}}{\sigma^{2}} e^{\left(\frac{-T_{p}^{2}}{2 \sigma^{2}}\right)}
$$

where $\sigma$ is the standard deviation of the process.

In this study, $\sigma$ is the standard deviation of the combined LF and WF load process and it can be 
formulated as

$$
\sigma=\sqrt{\sigma_{W}^{2}+\sigma_{L}^{2}}
$$

where $\sigma_{W}$ is the standard deviation of the WF tension process and $\sigma_{L}$ is the standard deviation of the LF tension process.

The zero up-crossing frequency of the combination tension, $v_{C i}$, can be expressed as

$$
v_{C}=\sqrt{\lambda_{L} v_{L}^{2}+\lambda_{W} v_{W}^{2}}
$$

where

$$
\begin{aligned}
& \lambda_{L}=\frac{\sigma_{L}^{2}}{\sigma_{W}^{2}+\sigma_{L}^{2}} \\
& \lambda_{W}=\frac{\sigma_{W}^{2}}{\sigma_{W}^{2}+\sigma_{L}^{2}}
\end{aligned}
$$

where $v_{W}$ is the zero up-crossing frequency of the wave frequency tension spectrum and $v_{L}$ the zero upcrossing frequency of low frequency tension spectrum for a sea state.

\section{Palmgren-Miner's rule based fatigue analyses}

As aforementioned, the fatigue life of a mooring system is traditionally predicted by PalmgrenMiner's rule according to T-N or S-N curves and this kind of approach is generally well established.

According to the Palmgren-Miner's rule, the accumulated damage of a mooring line can be predicted by

$$
D=\sum \frac{n_{i}}{N_{i}}
$$

where $n_{i}$ is the number of cycles of a tension range $T_{i}$ or stress range $S_{i}$ in the loading process and $N_{i}$ is the number of cycles to failure under a constant tension range $T_{i}$ or stress range $S_{i}$. In general, $N_{i}$ can be determined from a design T-N or S-N curve corresponding to the tension range $T_{i}$ or stress range $S_{i}$.

\subsection{T-N curves based fatigue analysis}

As shown in Fig.6 (a) (API RP 2SK, 2008), T-N curves for different mooring lines and connecting links 
are generally expressed as

$$
N R^{M}=K
$$

where $M$ is the slope of a T-N curve and $K$ is the intercept parameter. $R$ means the ratio of tension-tension range to reference breaking strength (RBS) of the mooring line. The reference values of $M$ and $K$ for different mooring lines and connecting links are listed in Table 5(a).

If the RBS of a mooring chain is not available, it may be approximately estimated by API RP 2SK (2008)

$$
R B S(k N)=0.0211 d^{2}(44-0.08 d)
$$

where $d$ is diameter of a mooring chain.

According to the Palmgren-Miner's rule, the mean value of the accumulated fatigue damage $D$ for sea state $i$ can then be derived as

$$
D_{i}=\frac{n_{i}}{K} E\left(R^{M}\right)
$$

where $E\left(R^{M}\right)$ is the mean value of $R^{M}$ and it can be expressed as

$$
E\left(R^{M}\right)=\int\left(\frac{2 T_{p}}{R B S}\right)^{M} f\left(T_{p}\right) d T_{p}
$$

According to Section 3.4, the narrow-banded tension range acting on mooring lines can be assumed to follow the Rayleigh distribution. The expected fatigue damage $D_{i}$ for sea state $i$ taking into account the T-N curves thus can be reformulated as

$$
D_{i}=\frac{n_{i}}{K}\left(\sqrt{2} \sigma_{T}\right)^{M} \Gamma\left(1+\frac{M}{2}\right)
$$

where $\Gamma\left(\right.$ ) is the gamma function and $n_{i}$ is the number of tension cycles encountered in sea state $i . \sigma_{T}$ is the ratio of standard deviation of the combined LF and WF tension range to RBS.

\subsection{S-N curves based fatigue analysis}

For S-N curves based fatigue analysis, the same approach described in Section 4.1 can be applied and the tension range $T_{R}$ is replaced by the nominal stress range $S$. The fatigue damage can be calculated as

$$
D_{i}=\frac{n_{i}}{K}\left(\sqrt{2} \sigma_{s t}\right)^{M} \Gamma\left(1+\frac{M}{2}\right)
$$

where $\sigma_{s t}$ is the standard deviation of the nominal stress ranges. The nominal stresses $\sigma_{n}$ can be calculated 
as:

$$
\sigma_{n}=\frac{T}{A}
$$

where $A$ is the area of cross section. For chain links, $A$ can be considered as $\frac{1}{2} \pi d^{2}$.

The reference values of $M$ and $K$, and also typical S-N curves (DNVGL OS E301, 2015) for different mooring lines and connecting links are given in Table 5(b) and Fig.6(b).

\section{Fracture mechanics analysis}

It is generally agreed with that the fracture mechanics based approach is more rational than T-N curves or S-N curves based approach for fatigue assessment. In the present paper, the chain links of mooring lines are modelled and initial surface cracks are assumed to propagate at the surface of chain links. The stress intensity factor ranges are calculated based on mooring line tension ranges coupled with a FEM analysis.

\subsection{Paris law and stress intensity factor}

Fracture mechanics analysis for mooring chains is performed herein based on the Paris-Erdogan equation (Paris and Erdogan, 1963) and British Standard (BS) 7910 (2013). The chain link is treated as a round bar and an initial surface crack is assumed to propagate at the surface of a chain link.

Based upon the Paris-Erdogan equation, the crack depth $a$ can be estimated by

$$
\frac{d a}{d n}=C(\Delta K)^{m}
$$

where $n$ is the number of stress cycles, $C$ and $m$ are material constants. $\Delta K$ is the stress intensity factor range in a stress cycle and the stress intensity factor $K$ is defined as (BS7910, 2013):

$$
K=Y \sigma \sqrt{\pi a}
$$

where $Y$ is the stress intensity correction factor and $Y \sigma$ is calculated as:

$$
Y \sigma=M f_{w}\left(M_{m} k_{t m} M_{k m} \sigma_{m}+M_{b} k_{t b} M_{k b} \sigma_{b}\right)
$$

where $k_{t m}$ and $k_{t b}$ are the stress concentration factors.

For a semi-elliptical surface crack in a round bar as shown in Fig.7 (a), $M=f_{w}=M_{k m}=M_{k b}=1, M_{m}$ 
and $M_{m}$ are given in Table 6.

For a semi-circle surface crack in a round bar as shown in Fig.7 (b), $M=f_{w}=M_{k m}=M_{k b}=1$, and $M_{m}$ and $M_{b}$ are given by

$$
\begin{aligned}
& M_{m}=g\left\{0.752+2.02\left(\frac{a}{2 r}\right)+0.37\left[1-\sin \left(\frac{\pi a}{4 r}\right)\right]^{3}\right\} \\
& M_{b}=g\left\{0.923+0.199\left[1-\sin \left(\frac{\pi a}{4 r}\right)\right]^{4}\right\}
\end{aligned}
$$

where

$$
g=\frac{\frac{1.84}{\pi}\left[\tan \left(\frac{\pi a}{4 r}\right) /\left(\frac{\pi a}{4 r}\right)\right]^{0.5}}{\cos \left(\frac{\pi a}{4 r}\right)}
$$

where $r$ is as shown in Fig. 7 (b).

$\sigma_{m}$ and $\sigma_{b}$ are membrane and bending stresses acting on two round bars induced by the combined wave and low frequency tension.

\subsection{Finite element analysis}

A finite element (FE) analysis is performed to predict the tension-induced membrane and bending stresses acting on cross-sections of a studless chain link.

\subsubsection{Mooring chain model}

R4 grade common studless mooring chain links are main components of the top chains and bottom chains in designed mooring systems. For R4 grade chain material (DNVGL OS E302, 2015), the yield stress and tensile strength are as $580 \mathrm{~N} / \mathrm{mm}^{2}$ and $860 \mathrm{~N} / \mathrm{mm}^{2}$, respectively. A 3D finite element model for studless mooring chain links is built as shown in Fig.8 where the links are modelled with standard dimensions where the length $L$ and breadth $B$ are given by:

$$
L=6 d, \quad B=3.35 d
$$

where $d$ is the nominal diameter of chain link. The corrosion allowance is also considered during the geometry of each link.

The model is meshed with quadratic Hexahedron elements and the surface contract effects between 
two mooring chains are considered and the contact regions are meshed with quadratic quadrilateral contact/target elements as shown in Fig.9. Two end faces in the same half mooring chain are defined as symmetry planes. The tensile loadings are applied at the other two end faces with directions normal to the faces.

As suggested by Lassen et al. (2005), the outside of crown cross-section, the inner surface of the beginning of the bend area (close to intrados where the chain shank and the crown intersect) and the inner surface of weld section, as shown in Fig.10, are treated herein as three potential locations that are prone to fatigue failure.

Fig.11 shows typical distributions of normal stresses (along the $Z$ axis of local coordinate as shown in Fig.10) of weld, bend, and crown sections, respectively.

To demonstrate the validity of the FE model for mooring chain links, a FE analysis for a 5.25 -inch mooring chain link is performed to compare with the work of Vargas et al. (2004). The stress concentration factors (SCFs) at weld section, bend section and crown section of the mooring chain link calculated based on the FE model and those from Vargas et al. (2004) and their relative errors are listed in Table 7. As seen from the table, all of the relative errors are smaller than $4 \%$, which indicates that the results calculated based on the FE model are close enough to those achieved from the FE analysis performed by Vargas et al. (2004).

\subsubsection{Membrane and bending stresses}

Membrane and bending stresses acting on the cross-sections of mooring chains are calculated by linearizing the normal stresses of the cross-sections.

Membrane stress is the mean stress through the section thickness which is given by

$$
\sigma_{m}=\frac{1}{t} \int_{0}^{t} \sigma_{n o r}(x) d x
$$

where $t$ is the total shell thickness, $\sigma_{\text {nor }}(x)$ the normal stress, $x$ the local coordinate along the thickness direction as shown in Fig.11.

Bending stress is the component of stresses due to imposed loading that varies linearly across the section thickness and it can be calculated as 


$$
\sigma_{b}=\frac{6}{t^{2}} \int_{0}^{t} \sigma_{n o r}(x)\left(\frac{t}{2-x}\right) d x
$$

A linearization of stress distribution over a weld section is plotted in Fig. 12 as an example. As shown in Fig.12, the total normal stresses of the selected cross-section can be well fitted by the combination of membrane and bending stresses.

\section{Comparison between T-N curves, S-N curves, and FM based fatigue analyses}

A comparison between $\mathrm{T}-\mathrm{N}$ curves, $\mathrm{S}-\mathrm{N}$ curves, and fracture mechanics based fatigue analyses is made in this section. The four mooring systems ( $A, B, C$ and $D)$ designed for this semi-submersible, in which cases $A$ and $B$ are taut mooring systems and cases $C$ and $D$ are catenary mooring systems, are utilized for this comparison. Fatigue lives of mooring chains calculated by the T-N and S-N curves based approaches with/without considering the safety factors suggested by API (2008) and DNVGL (2015) are plotted in Figs. 13-16. Fatigue lives of weld section without/with considering a stress concentration factor (SCF), bend section, and crown section of mooring chains predicted by the FM approach are also plotted in Figs. 13-16.

In the fracture mechanics analysis, the chain link is treated as a round bar and a semi-elliptical shape surface crack with initial crack sizes of $(0.5 \mathrm{~mm}, 0.5 \mathrm{~mm})$ is assumed to propagate at the surface of a chain link. As recommended by Mathisen and Larsen (2004), the critical crack depths are set as $12 \%$ of the chain diameter at weld sections, $30 \%$ of the chain diameter at bend section and $15 \%$ of the chain diameter at crown section.

Figs. 13-16 show that fatigue lives predicted by the T-N and S-N curves based approaches without considering safety factor are quite different and the fatigue lives predicted by the S-N curves based approach are about $130 \%$ longer than those calculated by the T-N curves based approach. After applying the safety factor 3.0 suggested by the API (2008) for the T-N curves based approach and 5.0 suggested by the DNVGL (2015) for the S-N curves based approach, Figs. 13-16 show that the fatigue lives predicted by the S-N curves based approach are only about 39\% longer than those calculated by the T-N curves based approach and the T-N curves based approach is only slightly conservative than the S-N curves based approach for fatigue life prediction of mooring chains.

Regarding the fatigue life prediction using the fracture mechanics based approach, Figs. 13-16 show 
that fatigue lives of weld section of a mooring chain with a SCF of 2.0 are generally the shortest compared with those of bend and crown sections. Also, the predicted fatigue lives of weld sections are sensitive to the variation of SCF which is often depending on the welding quality. As it can be seen from Figs. 13-16, fatigue lives of mooring chain weld sections with a SCF of 2.0 are only $12.5 \%$ of the fatigue lives of mooring chain weld sections without considering a SCF. In addition, Figs. 13-16 show that the crown sections of mooring chains are prone to fatigue damage and the fatigue lives of crown sections are only $44 \%$ of those of bend sections and $18 \%$ of those of weld sections without considering a SCF.

Additionally, Figs. 13-16 show that the fatigue lives predicted by T-N curves, S-N curves, and FM based approaches are in general comparable if the safety factors suggested by API and DNVGL are considered in the T-N and S-N curves based approaches. Fatigue lives of weld sections considering a SCF of 2.0 predicted by the FM approach are quite close to those calculated by the T-N curves based approach considering the safety factor 3.0 suggested by the API (2008). Fatigue lives of crown sections estimated by the FM approach are only $1 \%$ longer than those predicted by the S-N curves based approach considering the safety factor 5.0 suggested by the DNVGL (2015).

Furthermore, Figs. 13-16 show that for the four mooring systems, mooring lines 1-8 are prone to fatigue failure compared to mooring lines 9-16 and the mooring line 4 of each mooring system is the line with the shortest fatigue life. Moreover, Figs.13-16 show that the fatigue lives of catenary mooring system ( $C$ and D Cases) are generally longer than those of taut mooring system ( $A$ and B Cases). Figs.13-16 also show that fatigue lives of Cases $A$ and $C$ are generally longer than those of Cases B and D, respectively. As mentioned in Section 2.2, the connecting links are considered in Cases A and C but not accounted for in Cases B and D. Therefore, it might be indicated that fatigue lives of mooring chains will be underestimated if without taking into account the influence of connecting links.

\section{Parametric study}

The fatigue damage predicted by the fracture mechanics based approach generally varies with the assumptions made in the fracture mechanics analysis, such as initial crack shapes, initial crack sizes and critical crack depths. In order to investigate the effects of these factors on the fatigue lives of mooring 
chains, a parametric study is carried out for mooring system in case A.

\subsection{Effect of initial crack shapes}

Two types of initial surface crack shapes are considered in the fracture mechanics analysis, namely semi-elliptical surface crack and semi-circle surface crack. The comparison of the fatigue lives of crown sections of mooring chains predicted with the initial semi-elliptical surface cracks and the initial semi-circle surface cracks is carried out for the mooring system Case A and the results are plotted in Fig. 17.

Fig. 17 show that the fatigue lives calculated with these two types of initial surface crack shapes share the same trends for each mooring system. The fatigue life of each mooring chain in each case calculated with the initial semi-elliptical surface crack is $15 \%$ longer than that calculated with the initial semi-circle surface crack.

\subsection{Effect of initial crack sizes}

How to estimate the initial crack sizes of mooring chains relating to different mooring chain diameters is not clarified in the literature. Fig. 18 show that how to set the initial crack sizes is another key factor for accuracy fatigue lives estimation of mooring chains.

Fatigue lives of crown sections of mooring chains of the mooring system Case A calculated based on different initial crack sizes for Case $A$ are plotted in Fig. 18 where the assumed initial crack sizes $\left(\mathrm{a}_{0}, \mathrm{c}_{0}\right)$ are selected as $(0.4 \mathrm{~mm}, 0.4 \mathrm{~mm}),(0.5 \mathrm{~mm}, 0.5 \mathrm{~mm}),(0.6 \mathrm{~mm}, 0.6 \mathrm{~mm})$, and $(0.7 \mathrm{~mm}, 0.7 \mathrm{~mm})$.

Fig. 18 shows that the estimated fatigue lives decrease with the increase of initial crack sizes and the estimated fatigue lives calculated with initial crack sizes as $(0.4 \mathrm{~mm}, 0.4 \mathrm{~mm})$ are about $37 \%$ longer than those predicted with initial crack sizes as $(0.7 \mathrm{~mm}, 0.7 \mathrm{~mm})$ for identical mooring chains in this parametric study. It demonstrates that the fatigue lives of mooring chains are generally sensitive to the assumed initial crack sizes and proper choice of the initial crack sizes is one of key factors for accurate fatigue life prediction of mooring chains.

\subsection{Effect of critical crack depths}

Mathisen and Larsen (2004) suggested different critical crack depths for various locations of mooring 
chain links in fracture mechanics analysis. However, there is no particular reason given to explain why these critical crack depths were chosen. A parametric study to investigate the effect of critical crack depths on the fatigue lives of mooring chains is thus carried out in this Section.

The comparison of fatigue lives of crown sections of mooring chains of the mooring system Case A predicted based on different critical crack depths are performed and the results are shown in Fig. 19, in which the critical crack depths selected as $12 \%, 25 \%, 38 \%$ and $50 \%$ of mooring chain diameter are utilized for the parametric study.

Fig. 19 shows that fatigue lives calculated based on the critical crack depth chosen as $50 \%$ of mooring chain diameter are only $5 \%$ longer than those calculated based on the critical crack depth chosen as $13 \%$ of mooring chain diameter. It might be indicated that fatigue lives of crown sections of mooring chains predicted by the fracture mechanics analysis are insensitive to the critical crack depth.

The crack evolution of the mooring chain 4 is plotted in Fig. 20. It shows that it consumes about $95 \%$ of mooring chain fatigue life for the crack propagation from start to $10 \%$ of mooring chain diameter. The crack would grow rapidly after reaching $10 \%$ of the diameter. That might be the reason that the effect of critical crack depths on fatigue life of mooring chain is not significant when the critical crack depth is set more than $12 \%$ of mooring chain diameter in this study.

\section{Conclusions}

Mooring fatigue analyses for a semi-submersible operated at the central of Gulf of Mexico were performed using T-N curves, S-N curves, and fracture mechanics based approaches. The semi-submersible is spread moored with chain-fibre-chain mooring lines. A frequency-domain analysis was performed to estimate the combined loading process induced by the motions of wave frequency (WF) and low frequency (LF). In the fracture mechanics analysis, the chain links of mooring lines were treated as round bars and initial surface cracks were assumed to propagate at the surface of chain links. The stress intensity factor ranges were then calculated based on mooring line tension ranges coupled with a finite element analysis.

Fatigue life prediction of mooring chains at fairlead performed by $\mathrm{T}-\mathrm{N}$ curves, S-N curves, and fracture mechanics based fatigue analyses for designed mooring system Cases A, B, C and D was conducted. 
The results showed:

- The fatigue lives predicted by T-N curves, S-N curves, and FM based approaches are in general comparable if the safety factors suggested by API and DNVGL are considered in T-N and S-N curves based approaches.

- The T-N curves based approach is slightly conservative than the S-N curves based approach for fatigue life prediction of a mooring chain.

- Fatigue life of a chain link weld section is very sensitive to the SCF that is primarily depending on the welding quality.

- The crown section of a mooring chain is prone to fatigue damage compared to the bend section and the weld section without considering the SCF.

A parametric study to determine the influence of initial crack shape, critical crack depth and initial crack sizes on fatigue life prediction of mooring chains in the fracture mechanics analysis was carried out and the results showed:

- The fatigue life of a mooring chain calculated based on the initial semi-circle surface crack may be shorter than that calculated based on the initial semi-elliptical surface crack.

- $\quad$ Fatigue life of a mooring chain is generally sensitive to the assumed initial crack sizes.

- Fatigue life of a mooring chain predicted by the fracture mechanics analysis is insensitive to the critical crack depth.

\section{References}

API RP 2FP1, 1993. Recommended Practice for Design, Analysis and Maintenance of Moorings for Floating Production Systems, First Edition. American Petroleum Institute.

API RP 2MET, 2014. Derivation of Metocean Design and Operating Conditions, First Edition. American Petroleum Institute.

API RP 2SK, 2008. Design and analysis of stationkeeping systems for floating structures, Third Edition. American Petroleum Institute.

Barltrop, N.D.P., 1998. Floating structures: a guide for design and analysis. The Centre for Marine and 
Petroleum Technology, Oilfield Publications Limited.

BS 7910, 2013. Guide on methods for assessing the acceptability of flaws in fusion welded structures. British Standard Institute.

de Laval, G., 1971. Fatigue tests on anchor chain cable. In: Proceedings of Offshore Technology Conference, OTC 1503, Dallas, Texas.

DNVGL OS E301, 2015. Offshore standard DNVGL-OS-E301: Position mooring. Det Norske Veritas and Germanischer Lloyd SE.

DNVGL OS E302, 2015. Offshore standard DNVGL-OS-E302: Offshore mooring chain. Det Norske Veritas and Germanischer Lloyd SE.

Gao, Z., Moan, T., 2007. Fatigue damage induced by nonGaussian bimodal wave loading in mooring lines. Applied Ocean Research, 29, 45-54.

Garza-Rios, L.O., Bernitsas, M.M., Nishimoto, K., 1997. Catenary mooring lines with nonlinear drag and touchdown. University of Michigan.

Horde, G.O., Moan, T., 1997. Fatigue and overload reliability of mooring systems. In: Proceedings of the Seventh International Offshore and Polar Engineering Conference. International Society of Offshore and Polar Engineers, Honolulu, USA.

Kvitrud, A., 2014. Lessons learned from norwegian mooring line failures 2010-2013. In: Proceedings of the ASME 2014 33rd International Conference on Ocean, Offshore and Arctic Engineering. OMAE201423095. San Francisco, California, USA.

Lardier, J., Moan, T., Gao, Z., 2008. Fatigue reliability of catenary mooring lines under corrosion effect. In: Proceedings of the ASME 27th International Conference on Ocean, Offshore and Arctic Engineering. OMAE2008. Estoril, Portugal.

Lassen, T., Syvertsen, K.,1997. Fatigue relaibility and life-cycle cost analysis of mooring chains. International Journal of Offshore and Polar Engineering, 7(2), 135-140.

Lassen, T., Arana, J.L., Henriksen, J., Holthe, N.K., 2005. Crack growth in high strength chain steel subjected to fatigue loading in a corrosive environment. In: Proceedings of 24th International Conference on Offshore Mechanics and Arctic Engineering. OMAE2005-67242. Halkidiki, Greece. 
Lereim, J.,1985. Summary of the 4-Year Research Project: Anchor Chain Cables Offshore. In: Proceedings of 17th Offshore Technology Conference, Houston, Texas.

Ma, K.T., Duggal, A., Smedley, P., L'Hostis, D., Shu, H., 2013. A historical review on integrity issues of permanent mooring systems. OTC 24025. In: Offshore Technology Conference, Houston, Texas, USA.

Mathisen, J., Larsen, K., 2004. Risk-based inspection planning for mooring chain. Journal of Offshore Mechanics and Arctic Engineering, 126, 250-257.

Olagnon, M., Guédé, Z., 2008. Rainflow fatigue analysis for loads with multimodal power spectral densities. Marine Structures 21, 160-176.

Palin-Luc, T., Pérez-Mora, R., Bathias, C., Domínguez, G., Paris, P. C., Arana, J. L., 2010. Fatigue crack initiation and growth on a steel in the very high cycle regime with sea water corrosion. Engineering Fracture Mechanics, 77, 1953-1962.

Paris, P.C., Erdogan, F., 1963. A critical analysis of crack propagation laws. J Basic Eng, 85(4), 528-534.

Pérez-Mora, R., Palin-Luc, T., Bathias, C., Paris, P. C., 2015. Very high cycle fatigue of a high strength steel under sea water corrosion: A strong corrosion and mechanical damage coupling. International Journal of Fatigue, 74, 156-165.

van Helvoirt, L.C., 1982. Static and fatigue tests on chain links and chain connecting links. In: Proceedings of Offshore Technology Conference, . OTC 4179, Houston, Texas.

Vargas, P.M., Hsu, T.M., Lee, W.K., 2004. Stress concentration factors for stud-less mooring chain links in fairleads. In: Proceedings of 23rd International Conference on Offshore Mechanics and Arctic Engineering, Vancouver, British Columbia, Canada.

Wirsching, P. H., Light, M. C.,1980. Fatigue under wide band random stresses. Journal of Structural Division, ASCE, 106(7), 1593-1607.

Wu, Y., Wang, T., Eide, $\varnothing$., Haverty, K.,2015. Governing factors and locations of fatigue damage on mooring lines of floating structures. Ocean Engineering, 96, 109-124.

Xu, T.J., Zhao, Y.P., Dong, G.H., Bi, C. W., 2014. Fatigue analysis of mooring system for net cage under random loads. Aquacultural Engineering, 58, 59-68. 
Table 1. Principal dimensions of the semi-submersible hull

\begin{tabular}{|l|l|}
\hline Parameter & Value \\
\hline Draft & $26.0 \mathrm{~m}$ \\
\hline Overall length & $96.0 \mathrm{~m}$ \\
\hline Column corner radius & $4.0 \mathrm{~m}$ \\
\hline Freeboard to top of column & $27.0 \mathrm{~m}$ \\
\hline Pontoon height & $10.0 \mathrm{~m}$ \\
\hline Pontoon width & $22.0 \mathrm{~m}$ \\
\hline Platform displacement & $98,000 \mathrm{t}$ \\
\hline
\end{tabular}

Table 2. Designed mooring systems the case study

\begin{tabular}{|l|l|l|l|}
\hline Case & Mooring pattern & Pretension & Connecting links in the model? \\
\hline A & Taut & $3152 \mathrm{kN}$ & Yes \\
\hline B & Taut & $3152 \mathrm{kN}$ & No \\
\hline C & Catenary & $2102 \mathrm{kN}$ & Yes \\
\hline D & Catenary & $2102 \mathrm{kN}$ & No \\
\hline
\end{tabular}

Table 3. Mooring line characteristics

\begin{tabular}{|l|l|l|l|}
\hline & Top chain & Polyester rope & Bottom chain \\
\hline Axial stiffness $(\mathrm{kN})$ & $1.973 \times 10^{6}$ & $7.771 \times 10^{4}$ & $1.973 \times 10^{6}$ \\
\hline Mass per meter $(\mathrm{t} / \mathrm{m})$ & 0.4598 & 0.05687 & 0.4598 \\
\hline Nominal diameter $(\mathrm{m})$ & 0.152 & 0.267 & 0.152 \\
\hline Equivalent diameter $(\mathrm{m})$ & 0.2736 & 0.230 & 0.2736 \\
\hline Minimum breaking load $(\mathrm{kN})$ & 17513 & 19424 & 17513 \\
\hline
\end{tabular}

Table 4. Environmental conditions of the central of Gulf of Mexico considered in the fatigue analysis

\begin{tabular}{|c|c|c|c|c|c|c|c|c|c|c|c|c|c|c|}
\hline \multirow[t]{2}{*}{ Bin } & \multicolumn{3}{|c|}{ Wave } & \multirow{2}{*}{$\begin{array}{l}\text { Wind } \\
(\mathrm{m} / \mathrm{s})\end{array}$} & \multirow{2}{*}{$\begin{array}{l}\text { Current } \\
(\mathrm{m} / \mathrm{s})\end{array}$} & \multicolumn{8}{|c|}{ Collinear direction (clockwise, toward North) } & \multirow{2}{*}{$\begin{array}{l}\text { Total } \\
(\%)\end{array}$} \\
\hline & $H_{s}$ & $T_{p}$ & $\gamma$ & & & 0 & 45 & 90 & 135 & 180 & 225 & 270 & 315 & \\
\hline 1 & 0.5 & 5 & 1 & 11 & 0.2 & 2.702 & 0.572 & 0.655 & 1.918 & 2.238 & 4.179 & 7.036 & 9.242 & 28.542 \\
\hline 2 & 0.5 & 7 & 1 & 11 & 0.2 & 1.890 & 0.397 & 0.559 & 1.578 & 1.746 & 3.041 & 4.656 & 6.847 & 20.714 \\
\hline 3 & 0.5 & 10 & 1 & 11 & 0.2 & 0.386 & 0.051 & 0.099 & 0.355 & 0.409 & 0.797 & 1.017 & 1.594 & 4.707 \\
\hline 4 & 1.1 & 13 & 1 & 11 & 0.2 & 0.032 & - & 0.009 & 0.009 & 0.001 & 0.025 & 0.045 & 0.070 & 0.192 \\
\hline 5 & 1.5 & 5 & 1 & 11 & 0.2 & 0.926 & 0.185 & 0.280 & 1.206 & 2.117 & 3.604 & 4.685 & 4.559 & 17.562 \\
\hline 6 & 1.5 & 9 & 1 & 11 & 0.2 & 1.211 & 0.208 & 0.355 & 1.395 & 1.870 & 3.109 & 4.818 & 4.332 & 17.299 \\
\hline 7 & 2.5 & 11 & 1 & 11 & 0.2 & 0.041 & 0.004 & 0.051 & 0.199 & 0.158 & 0.192 & 0.184 & 0.222 & 1.051 \\
\hline 8 & 2.7 & 6 & 1 & 11 & 0.2 & 0.330 & 0.077 & 0.575 & 1.557 & 1.616 & 1.758 & 1.891 & 1.509 & 9.313 \\
\hline 9 & 3.5 & 11 & 1 & 11 & 0.2 & - & 0.001 & 0.037 & 0.050 & 0.028 & 0.018 & 0.003 & 0.007 & 0.144 \\
\hline 10 & 4.7 & 6 & 1 & 13 & 0.2 & 0.020 & 0.008 & 0.039 & 0.095 & 0.077 & 0.043 & 0.030 & 0.041 & 0.352 \\
\hline 11 & 5.1 & 9 & 2 & 15 & 0.2 & 0.004 & 0.001 & 0.004 & 0.005 & - & - & 0.007 & 0.012 & 0.034 \\
\hline 12 & 8.3 & 6 & 2 & 21 & 0.3 & 0.001 & 0.008 & 0.004 & - & 0.008 & 0.011 & 0.049 & 0.008 & 0.089 \\
\hline Total(\%) & & & & & & 7.542 & 1.514 & 2.667 & 8.369 & 10.269 & 16.776 & 24.421 & 28.443 & 100 \\
\hline
\end{tabular}

Table 5(a). Parameters of $M$ and $K$ for mooring components (T-N curves)

\begin{tabular}{|l|l|l|}
\hline Mooring components & $M$ & $K$ \\
\hline Common studlink & 3.0 & 1000 \\
\hline Common studless link & 3.0 & 316 \\
\hline Baldt and Kenter connecting link & 3.0 & 178 \\
\hline
\end{tabular}

Table 5(b). Parameters of $M$ and $K$ for mooring components (S-N curves)

\begin{tabular}{|l|l|l|}
\hline curves)Mooring components & $M$ & $K$ \\
\hline Common studlink & 3.0 & $1.2 \times 10^{11}$ \\
\hline Common studless link & 3.0 & $6.0 \times 10^{10}$ \\
\hline
\end{tabular}


Table 6(a). Stress intensity magnification factors $M_{m}$ at the deepest point $(a)$ of a semi-elliptical surface crack in a round bar (BS7910, 2013)

\begin{tabular}{|c|c|c|c|c|}
\hline & $a / c$ & & & \\
\hline$a / r$ & 0.2 & 0.4 & 0.6 & 1 \\
\hline 0.1 & 0.52 & 0.594 & 0.637 & 0.646 \\
\hline 0.2 & 0.599 & 0.634 & 0.668 & 0.674 \\
\hline 0.4 & 0.76 & 0.755 & 0.751 & 0.723 \\
\hline 0.6 & 0.993 & 0.959 & 0.913 & 0.809 \\
\hline 0.8 & 1.357 & 1.288 & 1.191 & 0.952 \\
\hline 1 & 1.97 & 1.855 & 1.639 & 1.213 \\
\hline
\end{tabular}

Table 6(b). Stress intensity magnification factors $M_{m}$ at surface $(c)$ of a semi-elliptical surface crack in a round bar (BS7910, 2013)

\begin{tabular}{|c|c|c|c|c|}
\hline & $a / c$ & & & \\
\hline$a / r$ & 0.2 & 0.4 & 0.6 & 1 \\
\hline 0.1 & 0.114 & 0.315 & 0.525 & 0.717 \\
\hline 0.2 & 0.2 & 0.353 & 0.565 & 0.792 \\
\hline 0.4 & 0.358 & 0.498 & 0.649 & 0.88 \\
\hline 0.6 & 0.587 & 0.685 & 0.84 & 1.067 \\
\hline 0.8 & 0.946 & 1.040 & 1.116 & 1.387 \\
\hline 1 & 1.525 & 1.646 & 1.648 & 1.982 \\
\hline
\end{tabular}

Table 6(c). Stress intensity magnification factors $M_{b}$ at the deepest point ( $a$ ) of a semi-elliptical surface crack in a round bar (BS7910, 2013)

\begin{tabular}{|c|c|c|c|c|}
\hline & $a / c$ & & & \\
\hline$a / r$ & 0.2 & 0.4 & 0.6 & 1 \\
\hline 0.1 & 0.489 & 0.558 & 0.599 & 0.604 \\
\hline 0.2 & 0.523 & 0.554 & 0.582 & 0.582 \\
\hline 0.4 & 0.567 & 0.564 & 0.558 & 0.526 \\
\hline 0.6 & 0.629 & 0.608 & 0.576 & 0.491 \\
\hline 0.8 & 0.731 & 0.695 & 0.638 & 0.482 \\
\hline 1 & 0.91 & 0.858 & 0.754 & 0.523 \\
\hline
\end{tabular}

Table $6(\mathrm{~d})$. Stress intensity magnification factors $M_{b}$ at surface $(c)$ of a semi-elliptical surface crack in a round bar (BS7910, 2013)

\begin{tabular}{|l|l|l|l|l|}
\hline & $a / c$ & 0 & \\
\hline$a / r$ & 0.2 & 0.4 & 0.6 & 1 \\
\hline 0.1 & 0.107 & 0.305 & 0.511 & 0.702 \\
\hline 0.2 & 0.172 & 0.321 & 0.529 & 0.755 \\
\hline 0.4 & 0.254 & 0.384 & 0.537 & 0.779 \\
\hline 0.6 & 0.349 & 0.440 & 0.591 & 0.849 \\
\hline 0.8 & 0.477 & 0.560 & 0.657 & 0.961 \\
\hline 1 & 0.657 & 0.751 & 0.825 & 1.173 \\
\hline
\end{tabular}

Table 7. Stress concentration factors (SCFs) at weld section, bend section, and crown section of a 5.25-inch chain link calculated based on the FE model (SCF1) and those (SCF2) from Vargas et al. (2004) and also their relative errors

\begin{tabular}{|l|l|l|l|}
\hline & SCF1 & SCF2 & Relative error $=($ SCF1 - SCF2) $/$ SCF2 $\times 100 \%$ \\
\hline Weld section & 3.31 & 3.39 & $-2.4 \%$ \\
\hline Bend section & 3.89 & 3.74 & $4.0 \%$ \\
\hline Crown section & 4.39 & 4.33 & $1.4 \%$ \\
\hline
\end{tabular}




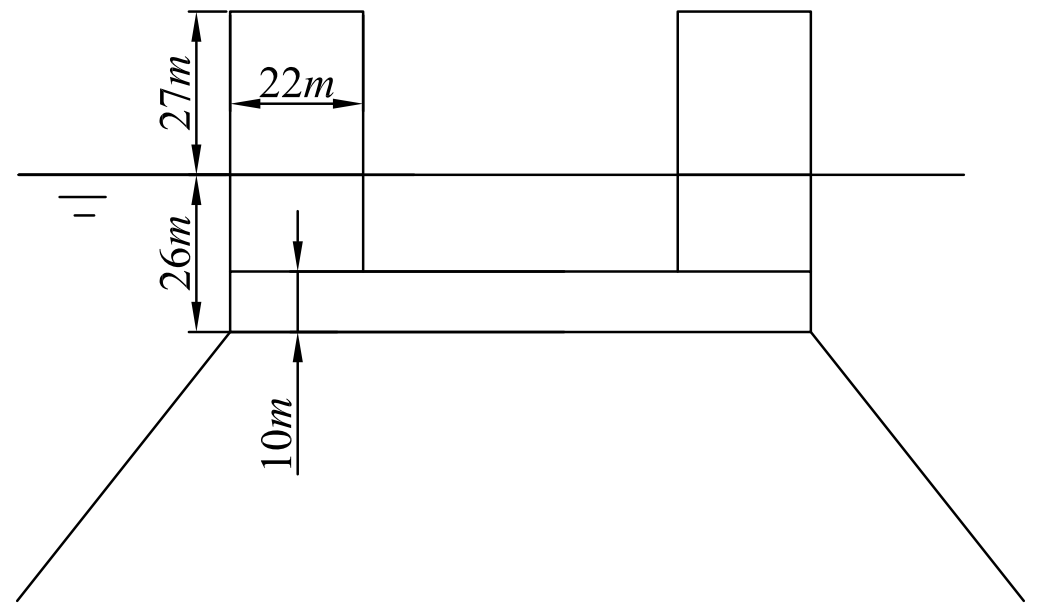

Fig. 1. Geometry of the semi-submersible 




Fig. 2. Layout of mooring lines of the semi-submersible 


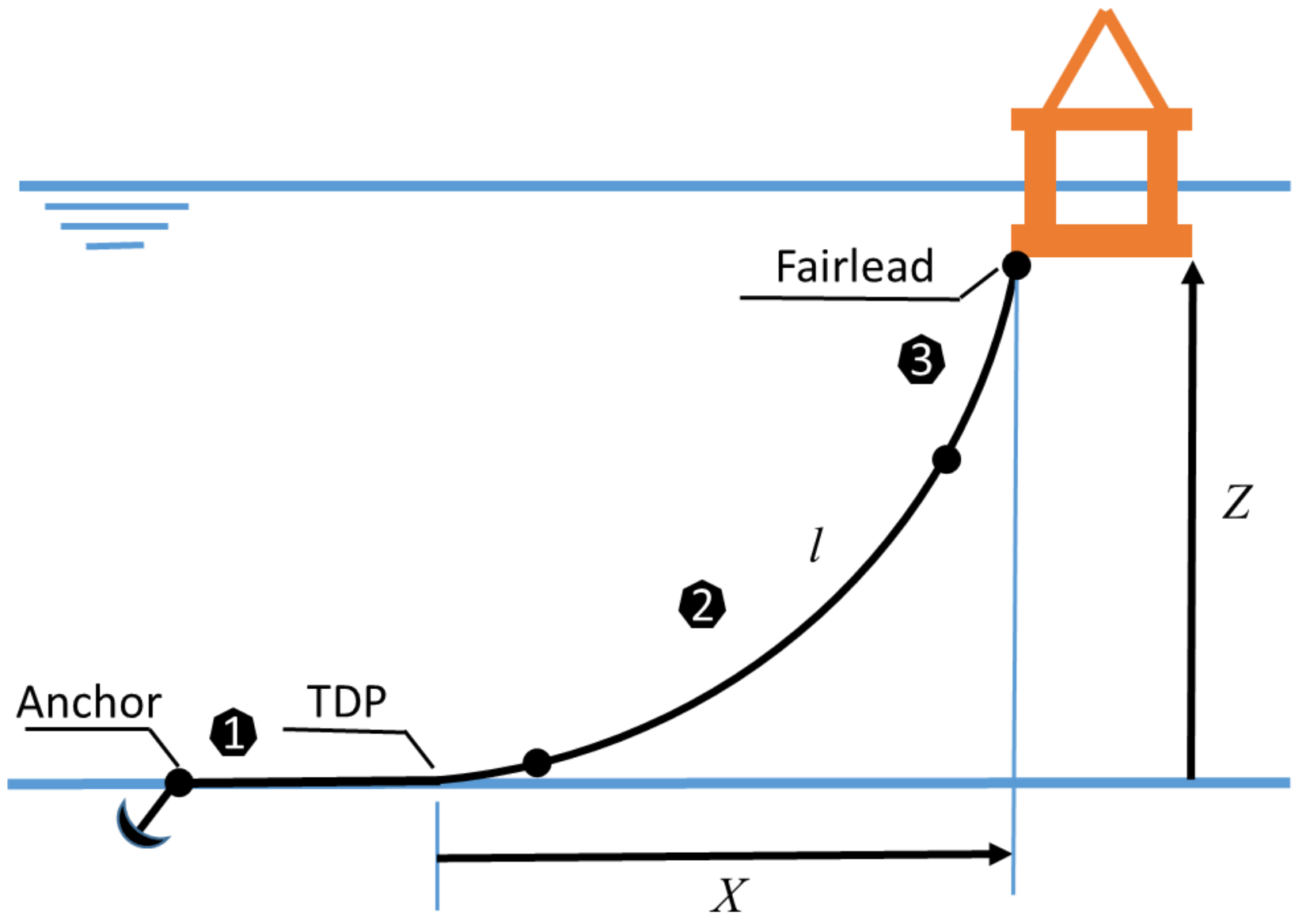

Fig. 3. Geometry of a 2D catenary mooring line 


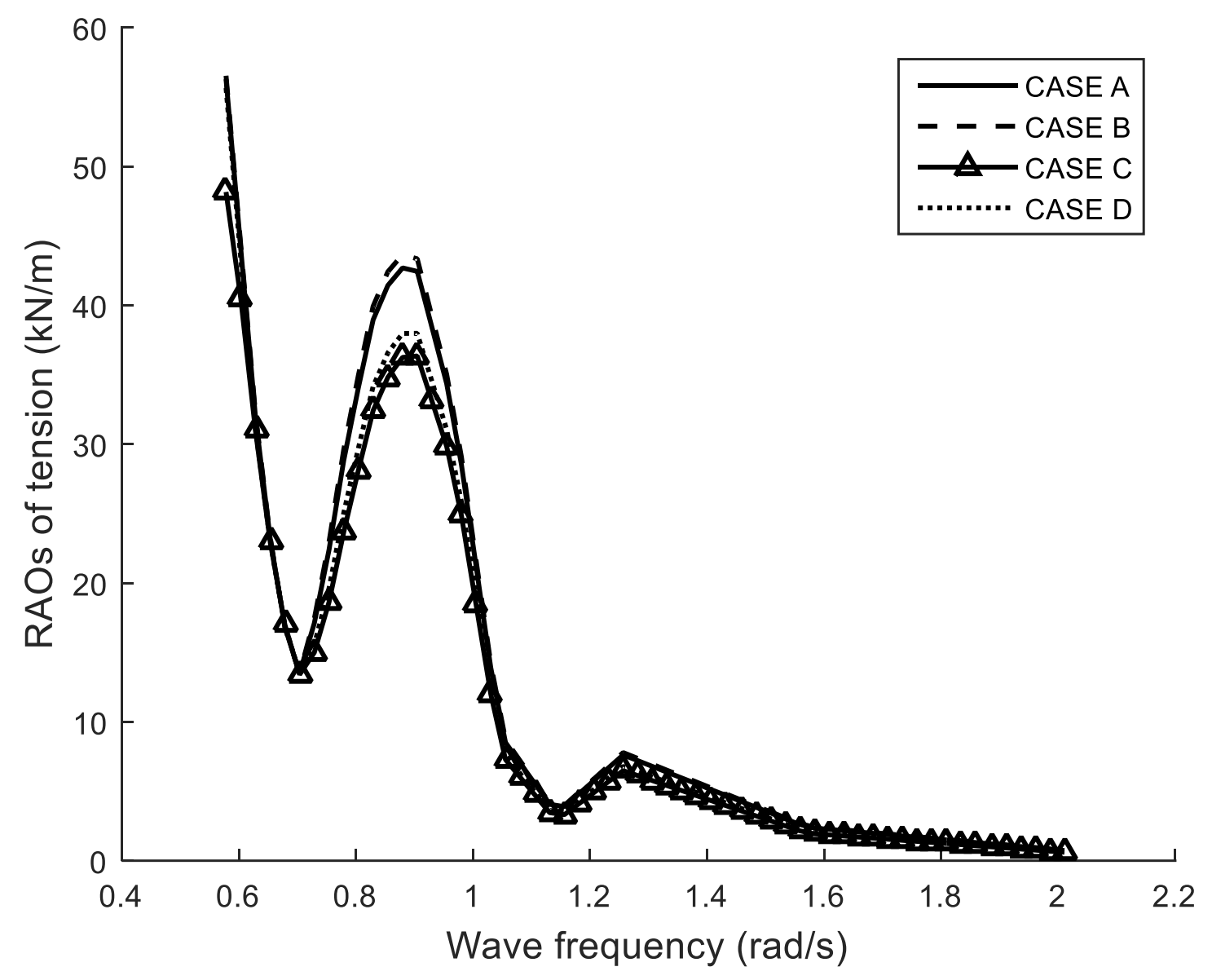

Fig. 4. RAOs of tension of mooring lines 


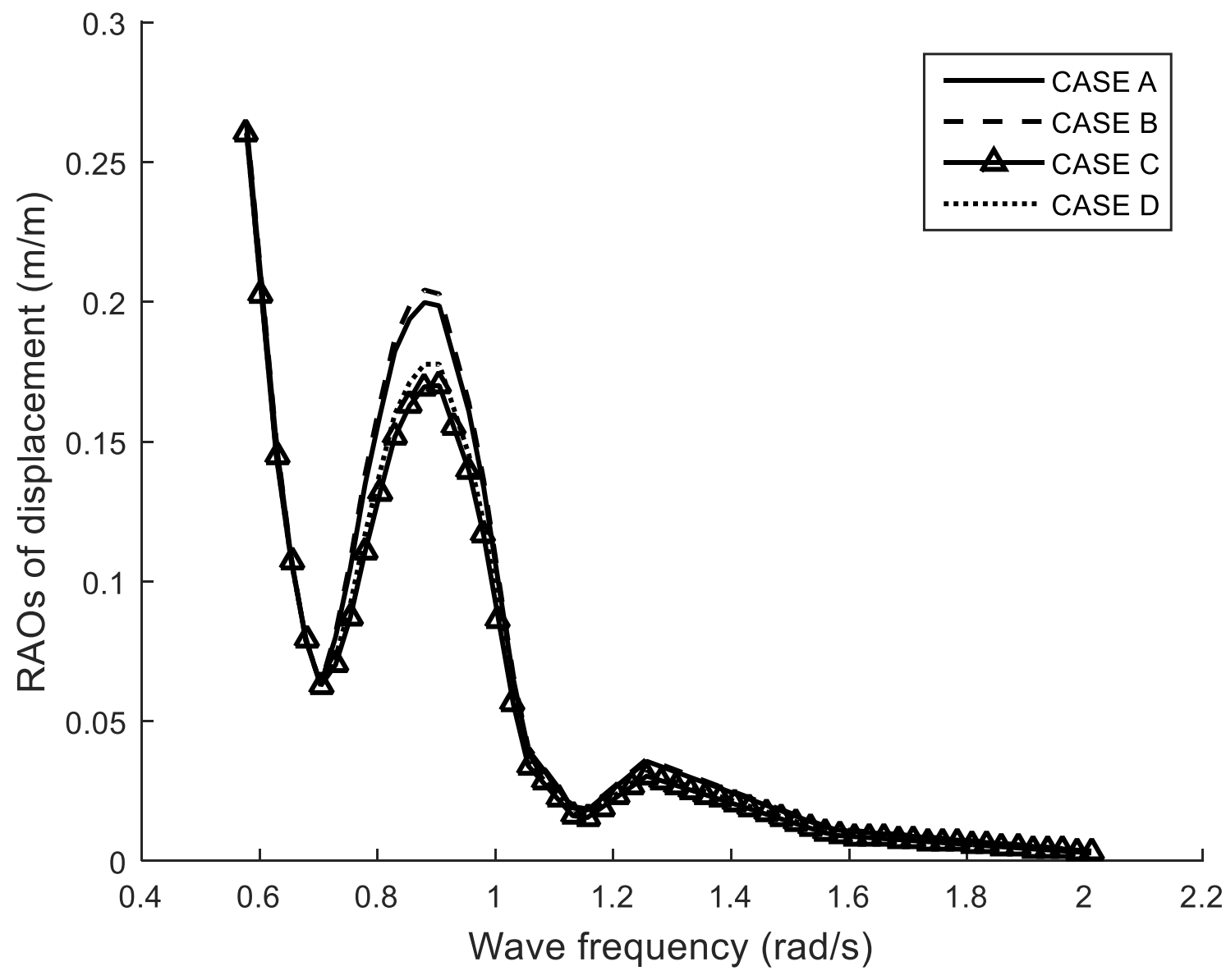

Fig. 5. RAOs of displacement of mooring lines in the direction of line tangent at fairleads 


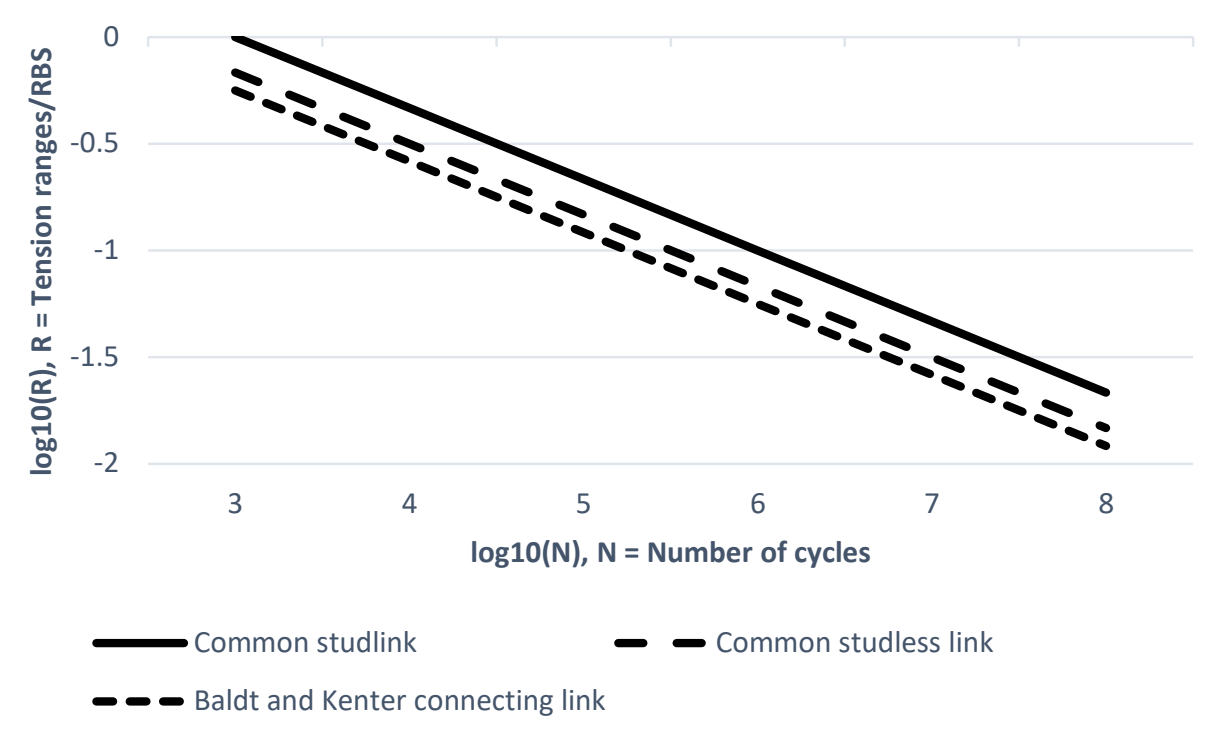

(a)

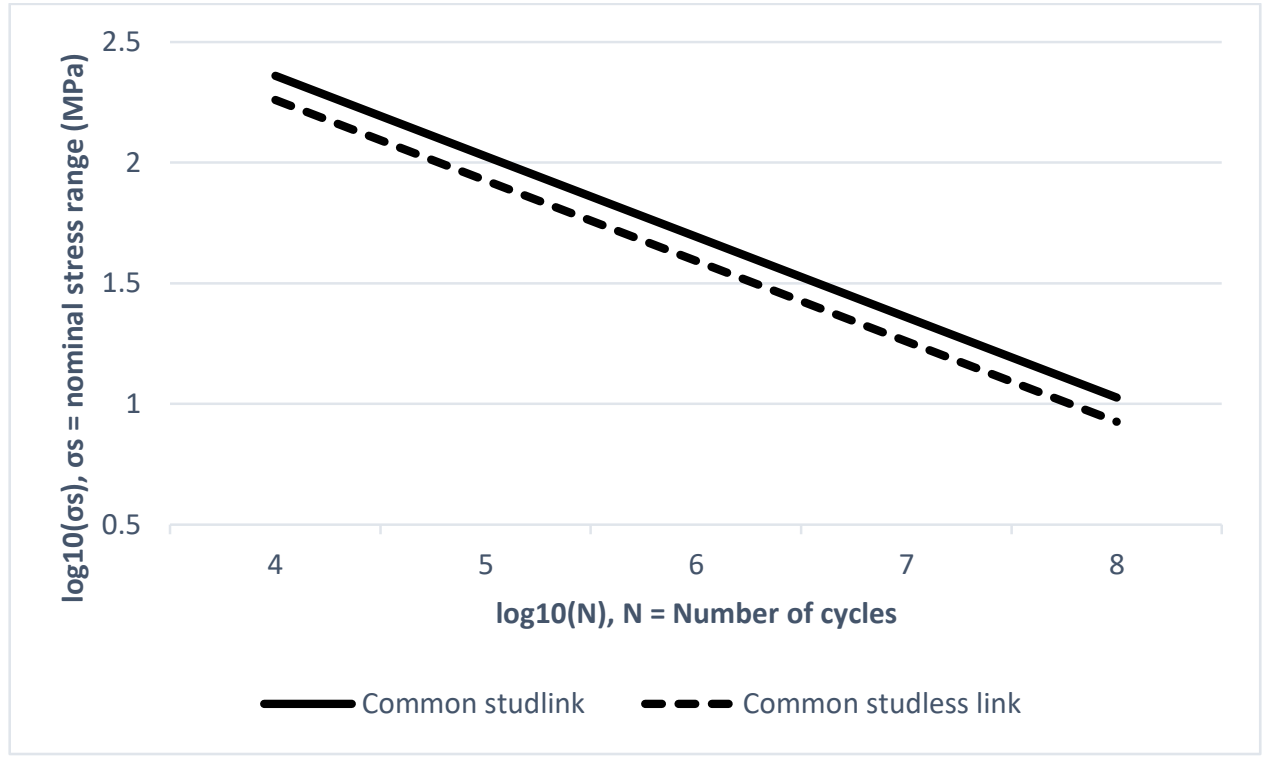

(b)

Fig. 6. T-N and S-N curves for mooring lines and components: (a) T-N curves; (b) S-N curves 


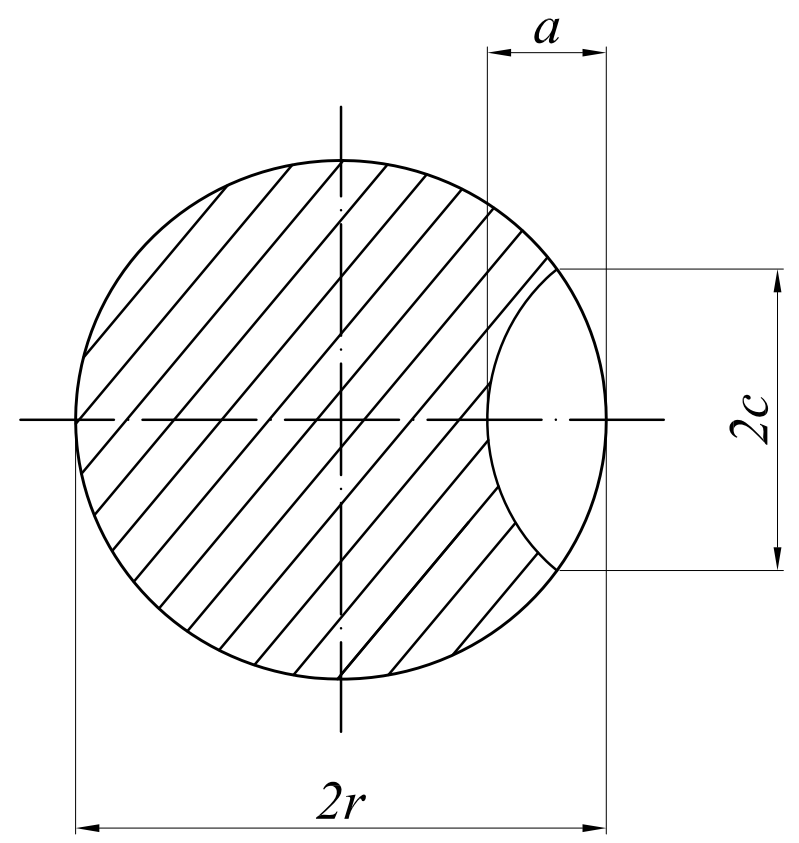

(a)

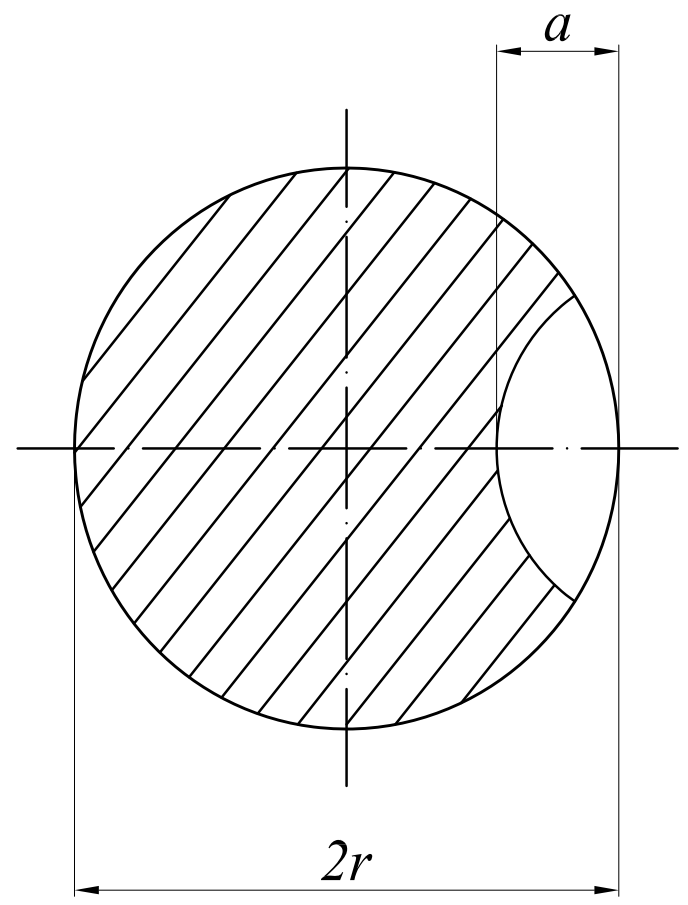

(b)

Fig. 7. Geometry of a round bar with a surface crack: (a) Semi-elliptical crack $(a / r \ll 1)$; (b) Semi-circle $\operatorname{crack}(a / r \ll 1.2)$ 


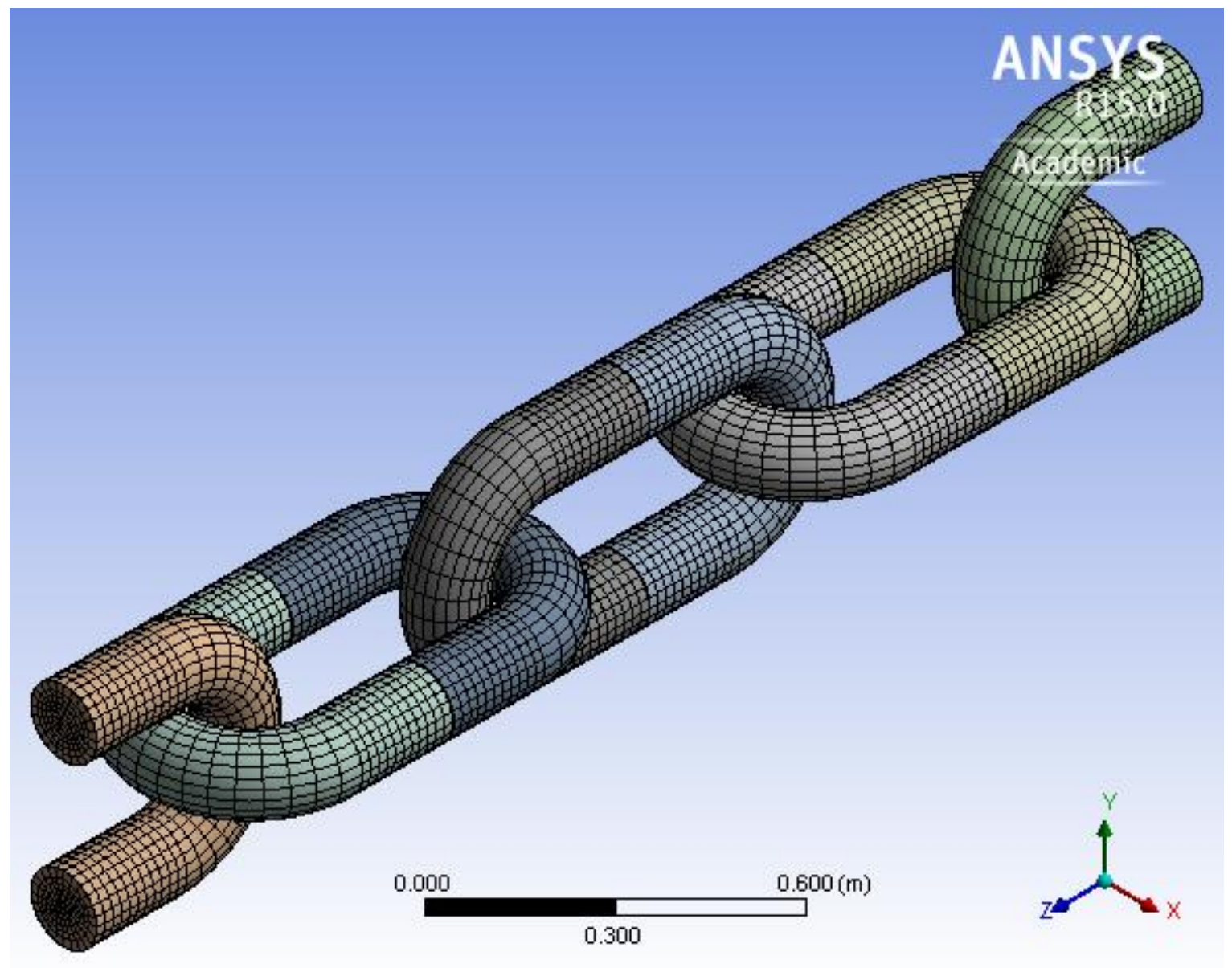

Fig. 8. Finite element model of mooring chain links 


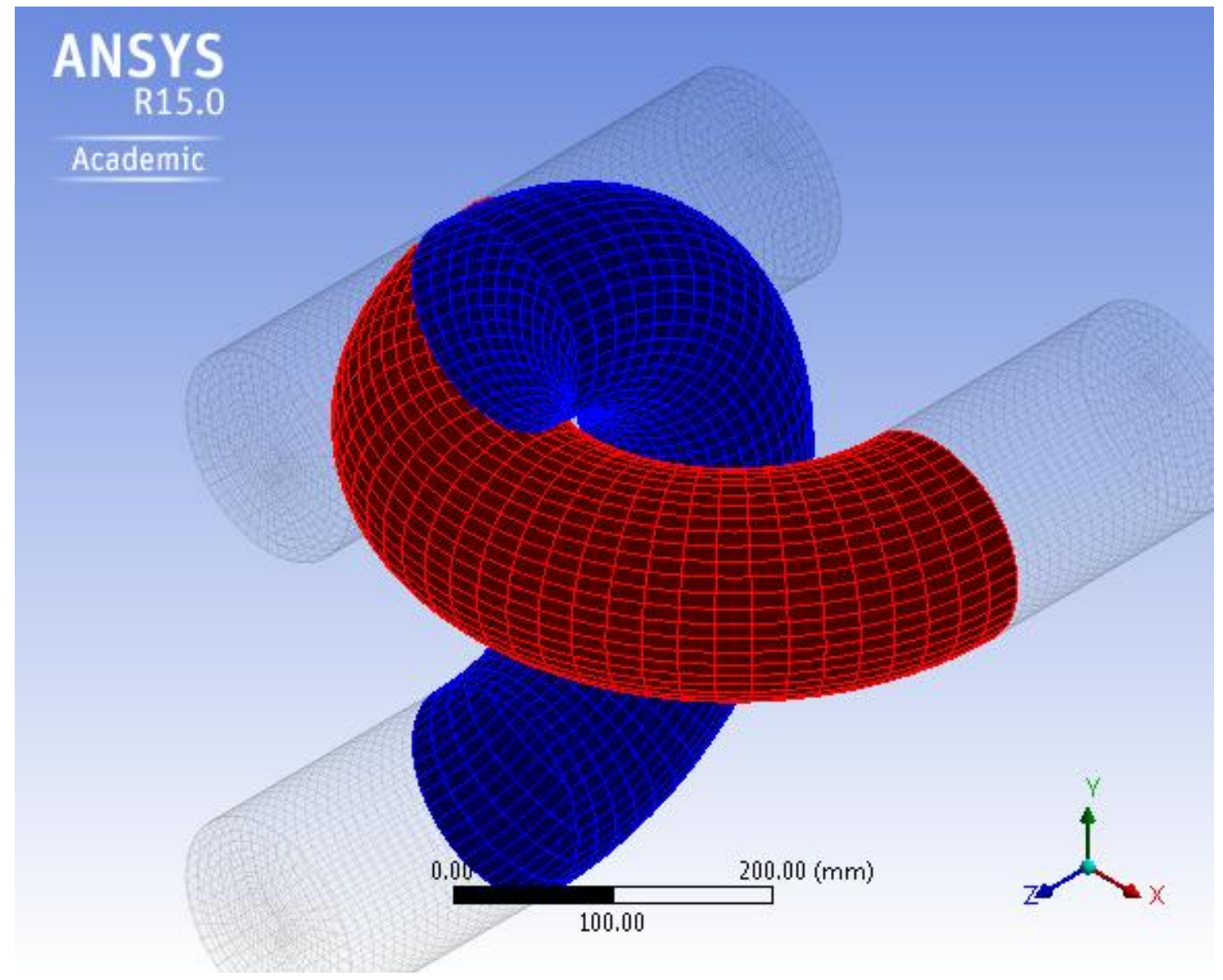

Fig. 9. Meshed contact elements of mooring chain links 


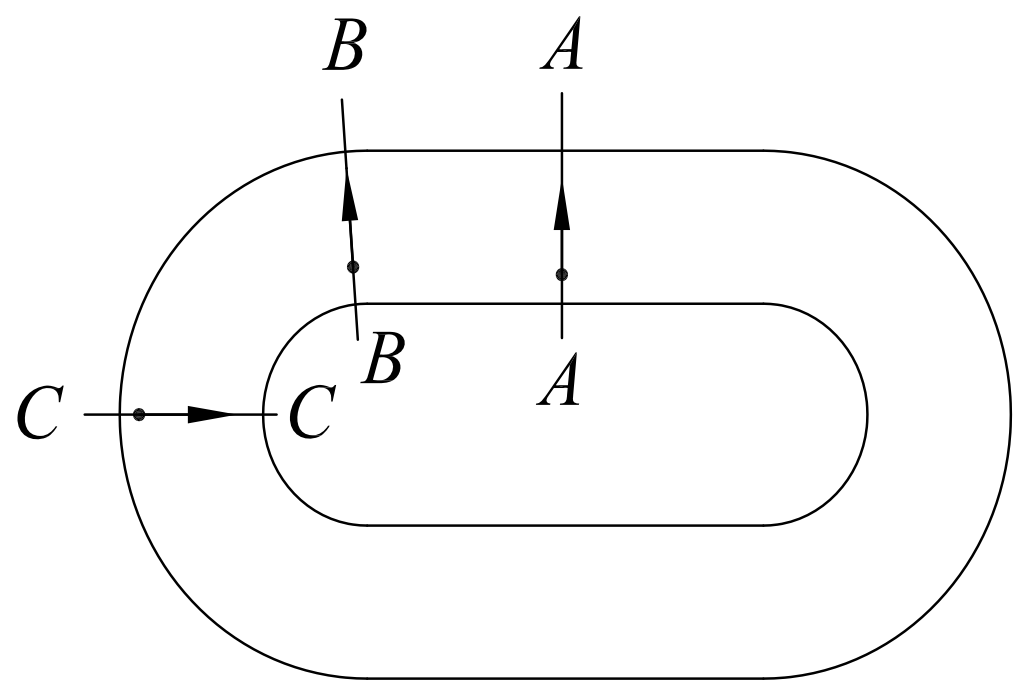

Fig. 10. Locations of a chain link prone to fatigue damage 




(a)

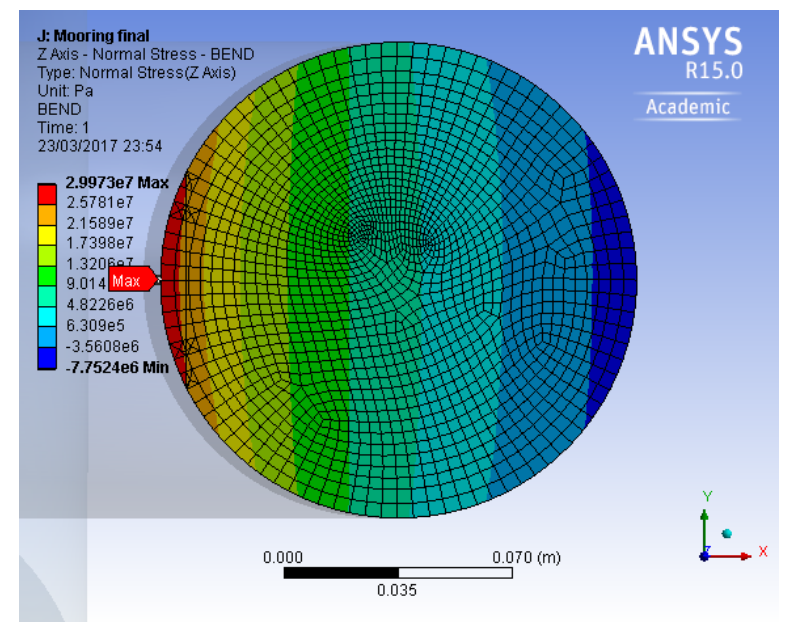

(b)

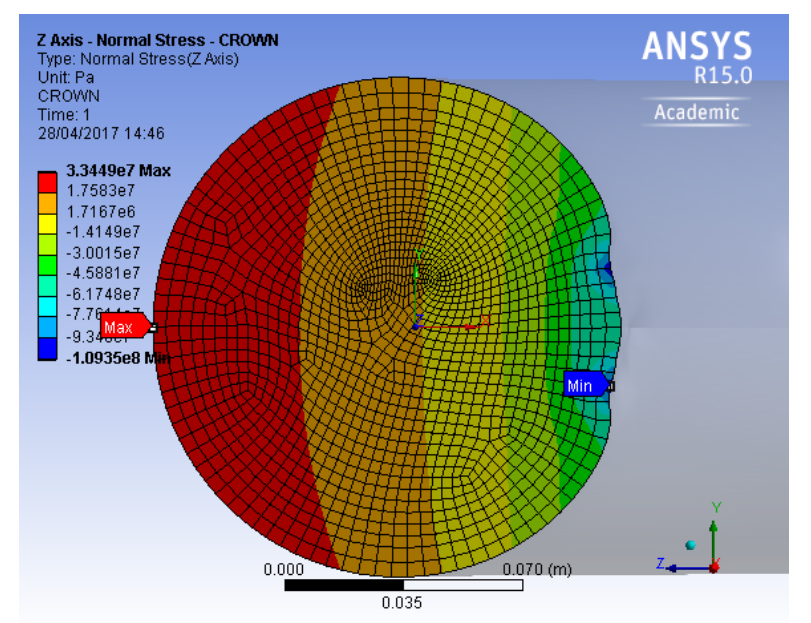

(c)

Fig. 11. Normal stresses at locations of the chain link prone to potential fatigue damage: (a) weld section; (b) bend section; (c) crown section 


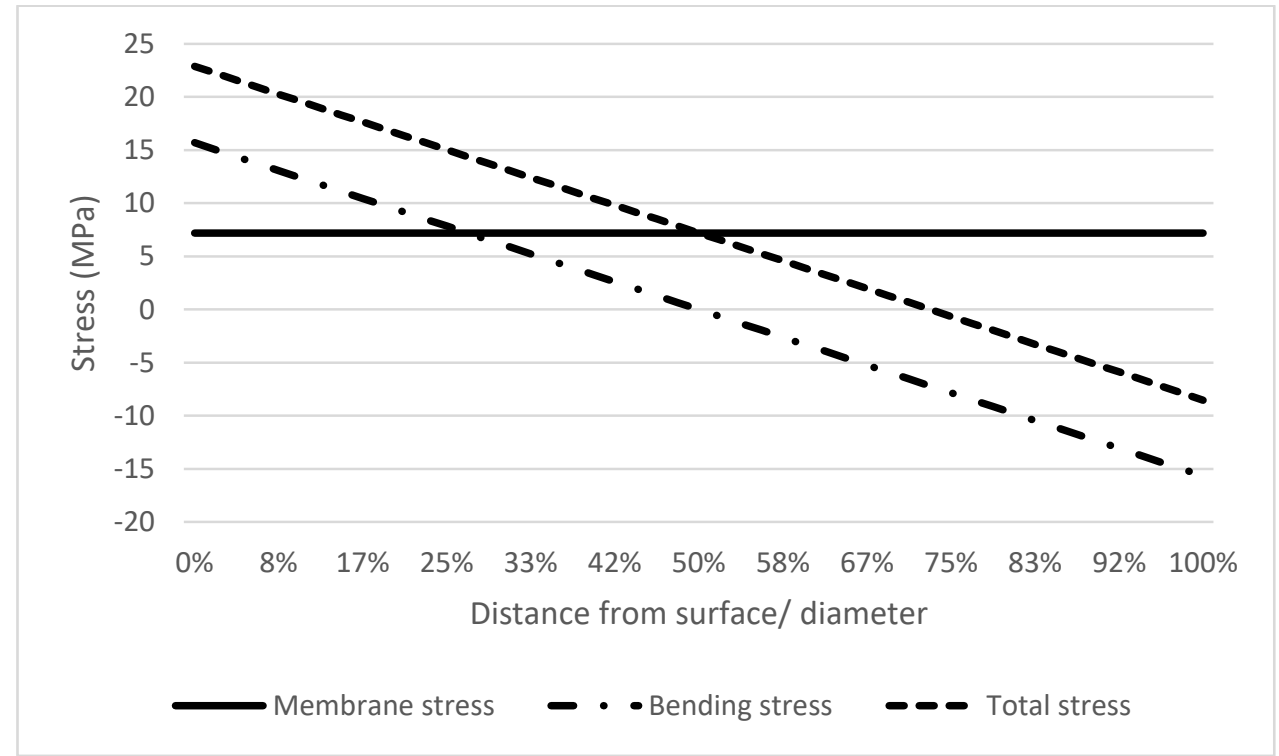

Fig. 12. Linearization of stress distribution over a weld section 


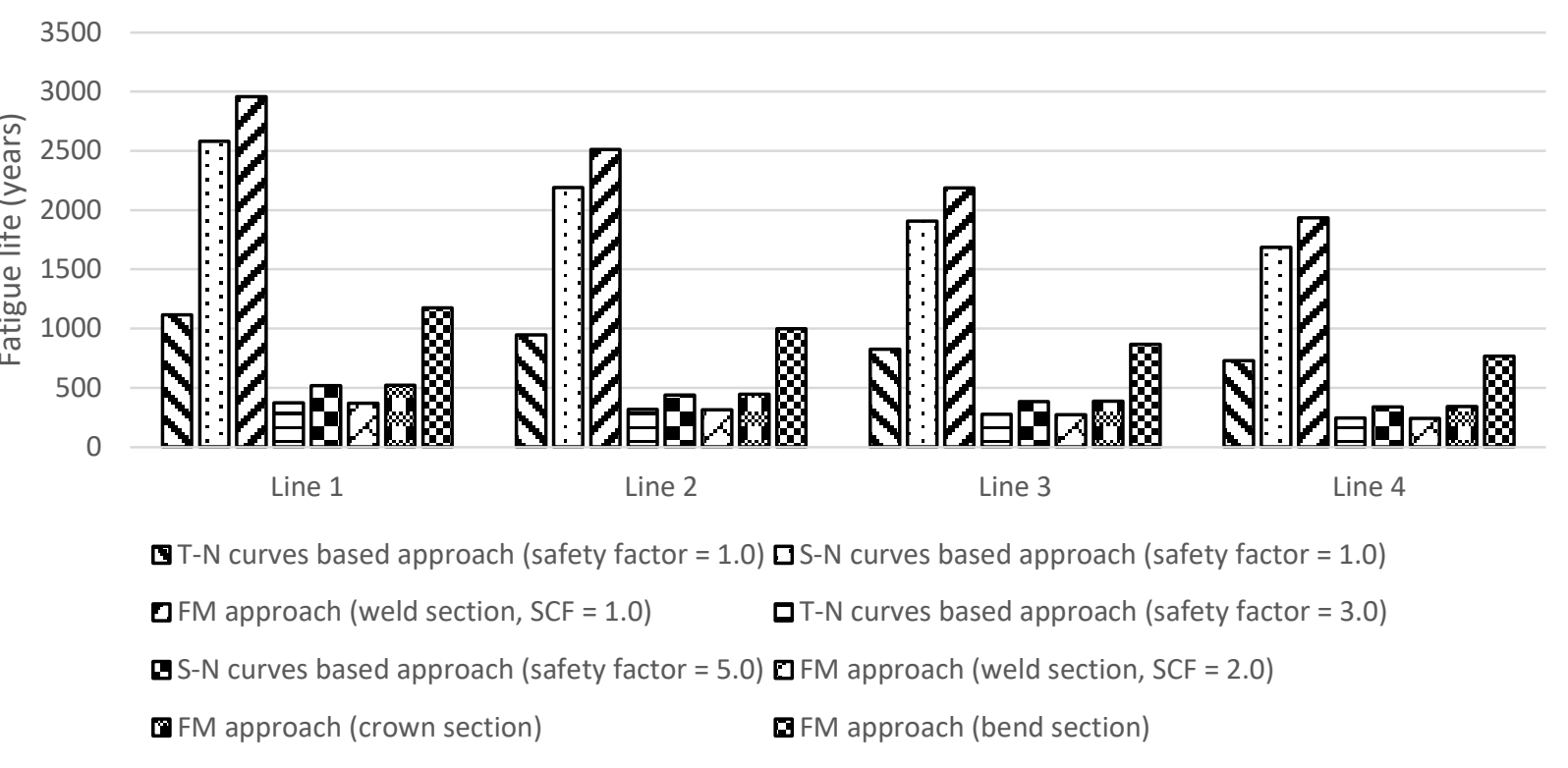

(a)

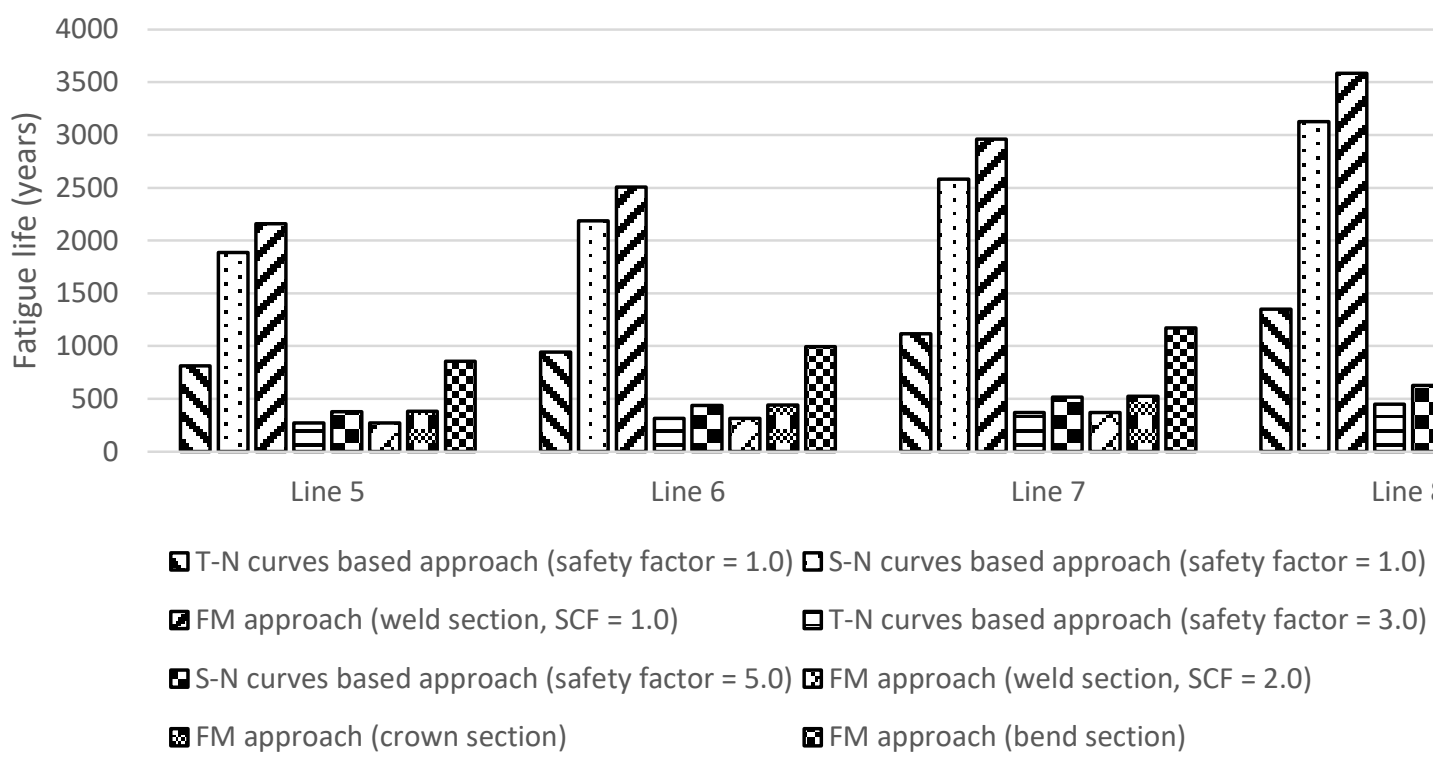

(b) 


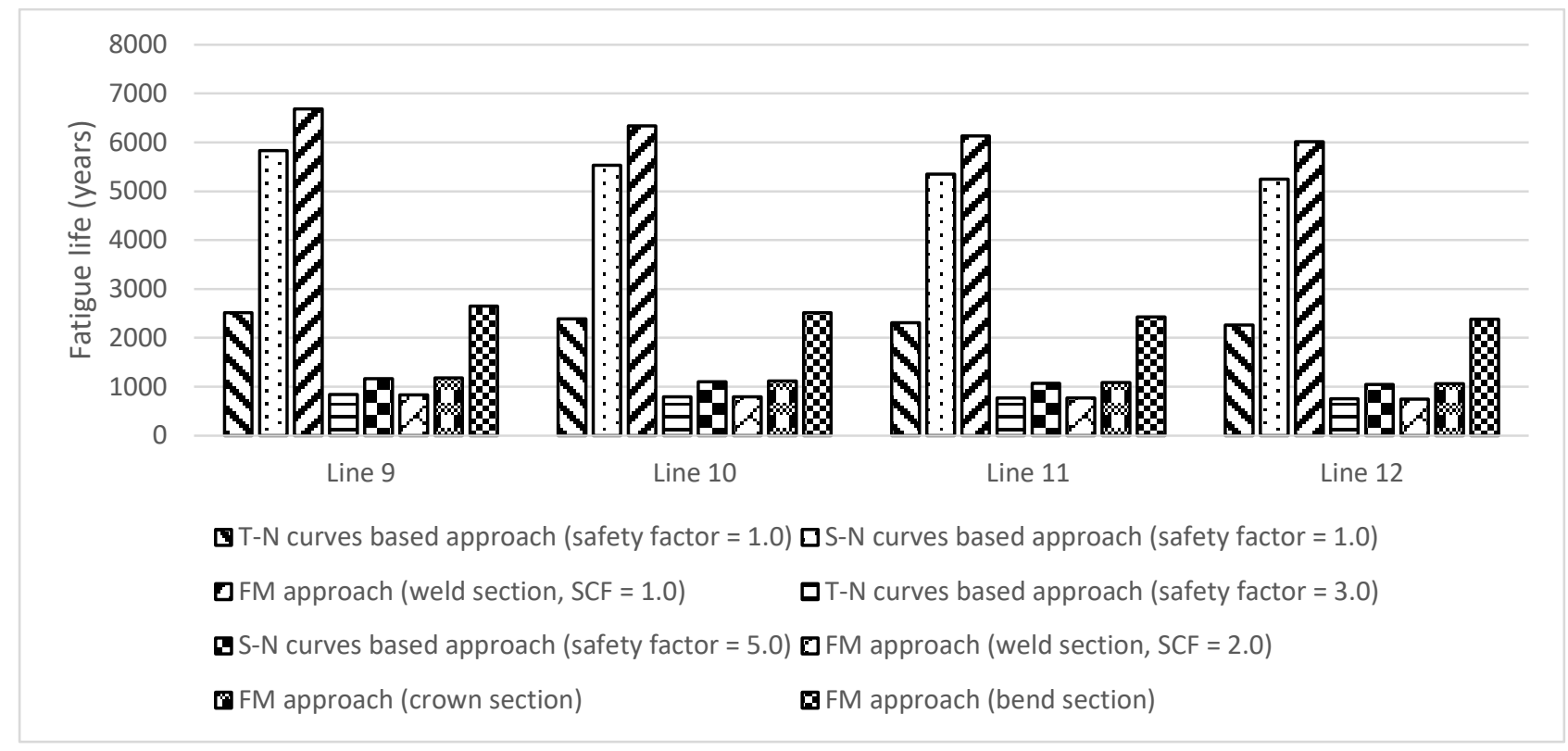

(c)

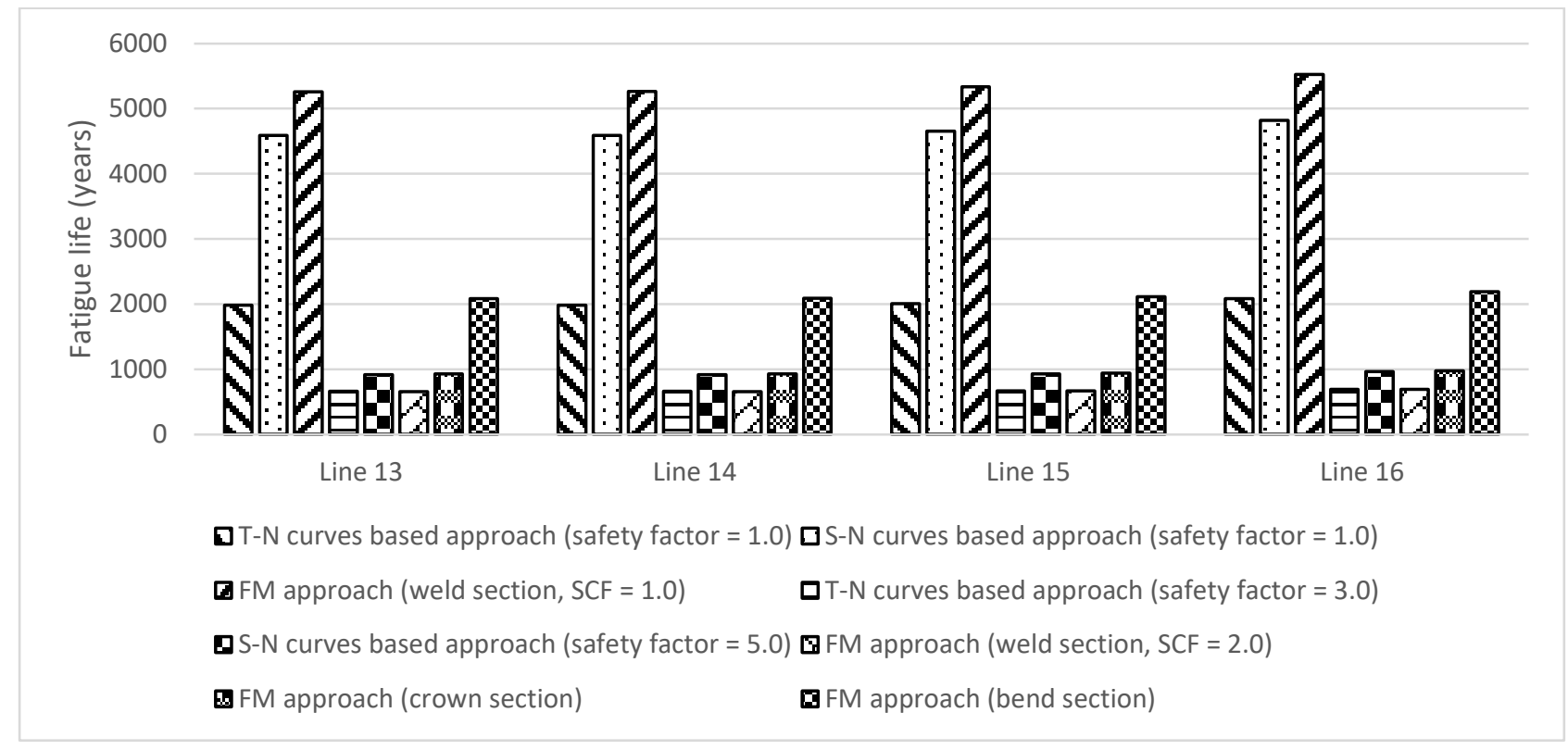

(d)

Fig. 13. T-N curves, S-N curves, and fracture mechanics based fatigue analyses for mooring chains subjected to the combined low frequency and wave frequency tension for Case A: (a) Line 1 to Line 4; (b) Line 5 to Line 8; (c) Line 9 to Line 12; (d) Line 13 to Line 16 




(a)

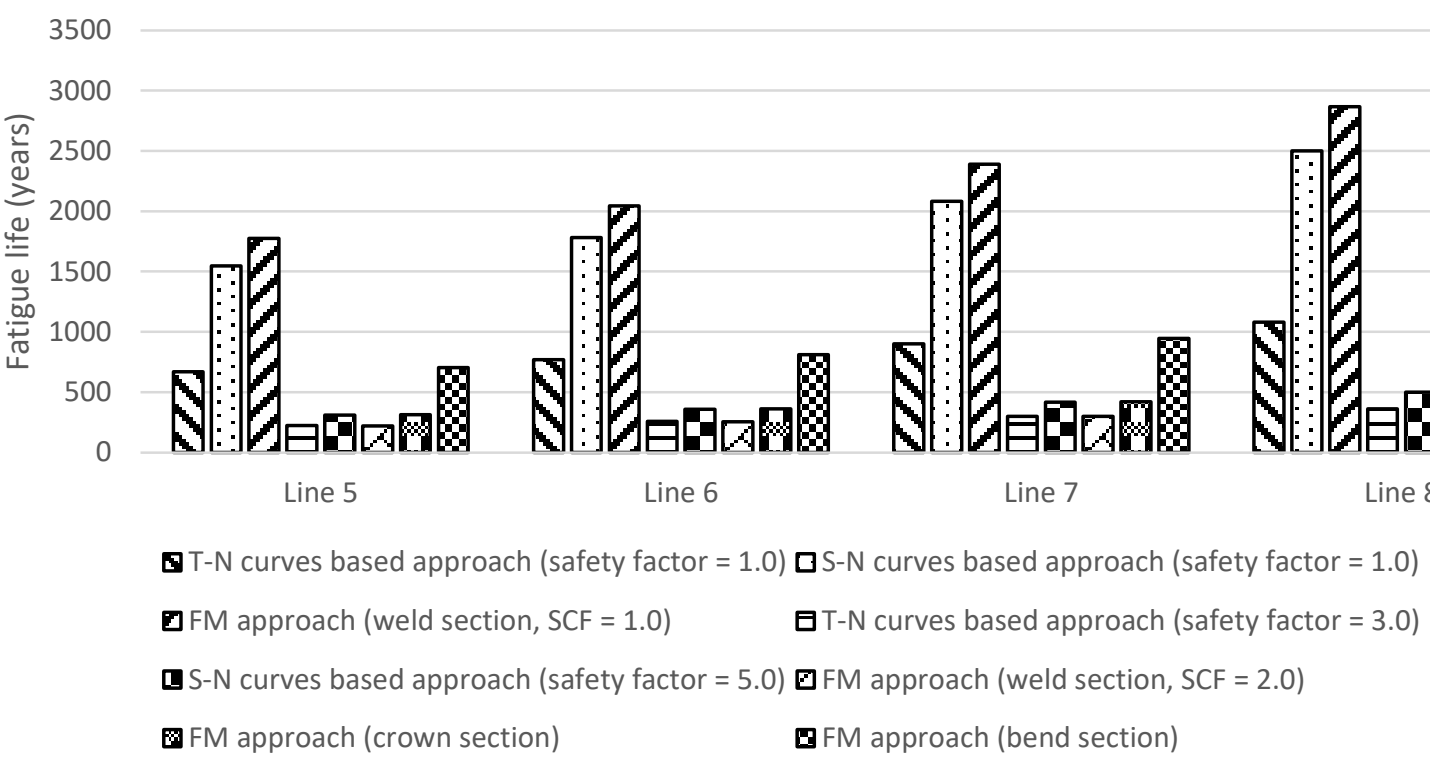

(b) 


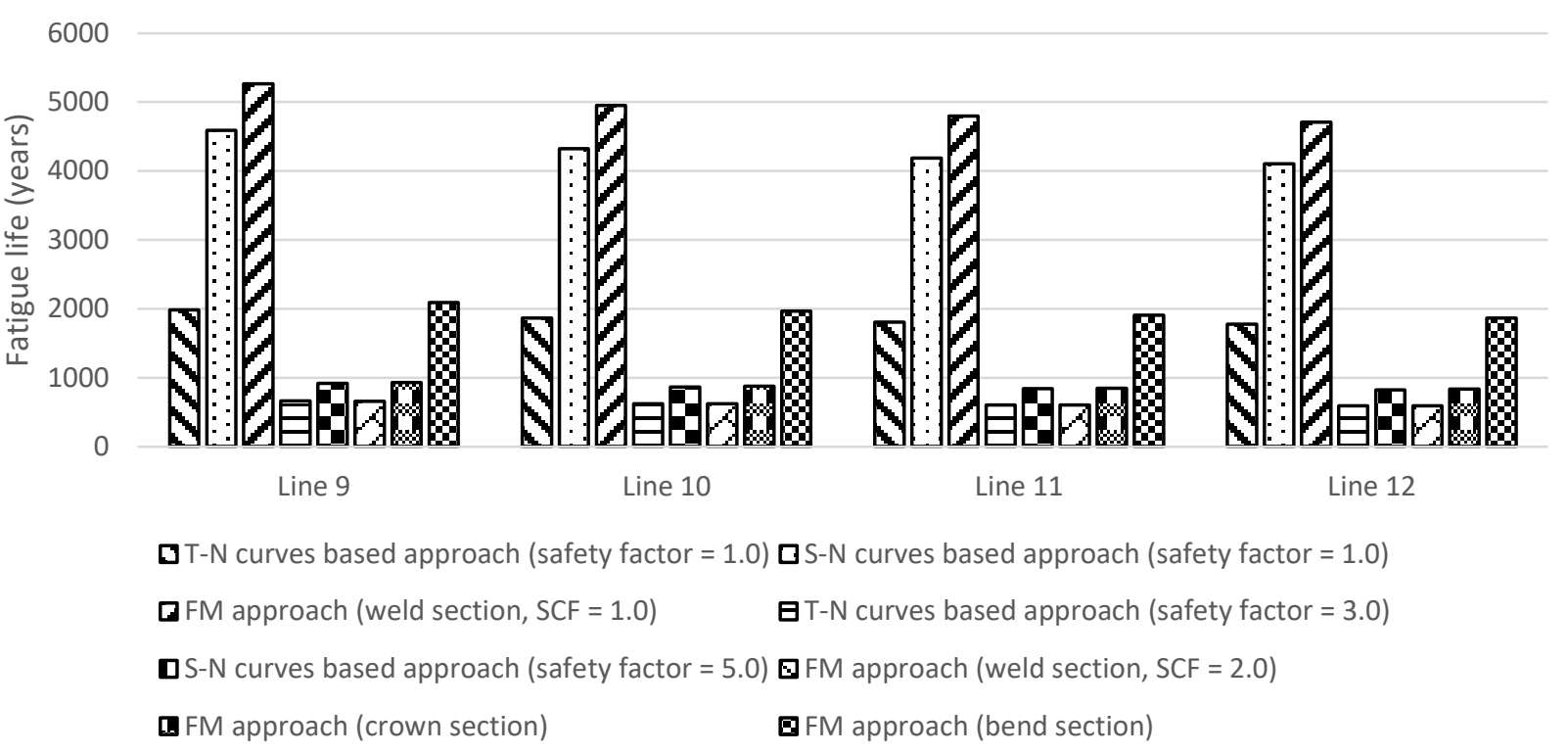

(c)

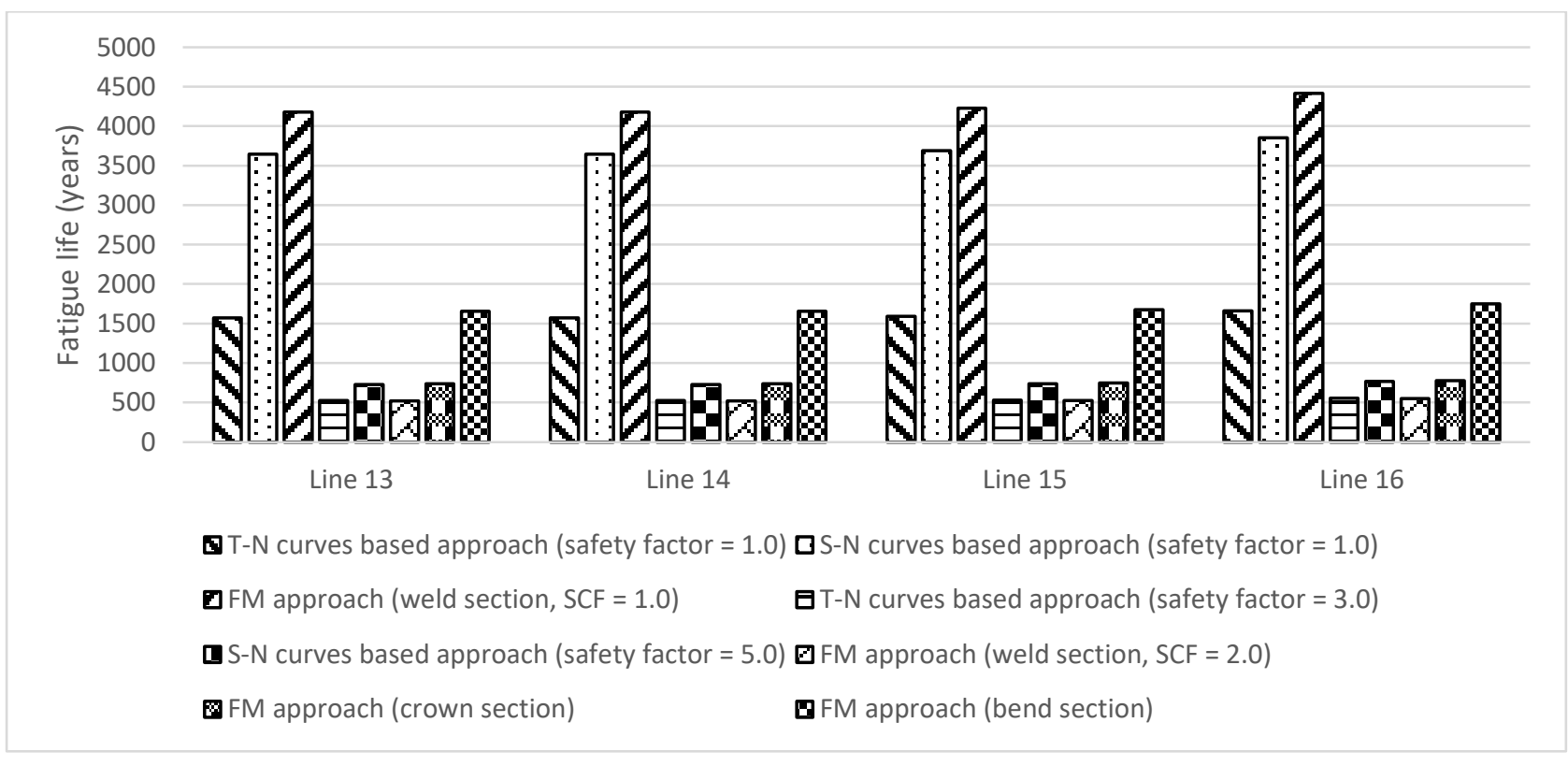

(d)

Fig. 14. T-N curves, S-N curves, and fracture mechanics based fatigue analyses for mooring chains subjected to the combined low frequency and wave frequency tension for Case B: (a) Line 1 to Line 4; (b) Line 5 to Line 8; (c) Line 9 to Line 12; (c) Line 9 to Line 12; (d) Line 13 to Line 16 


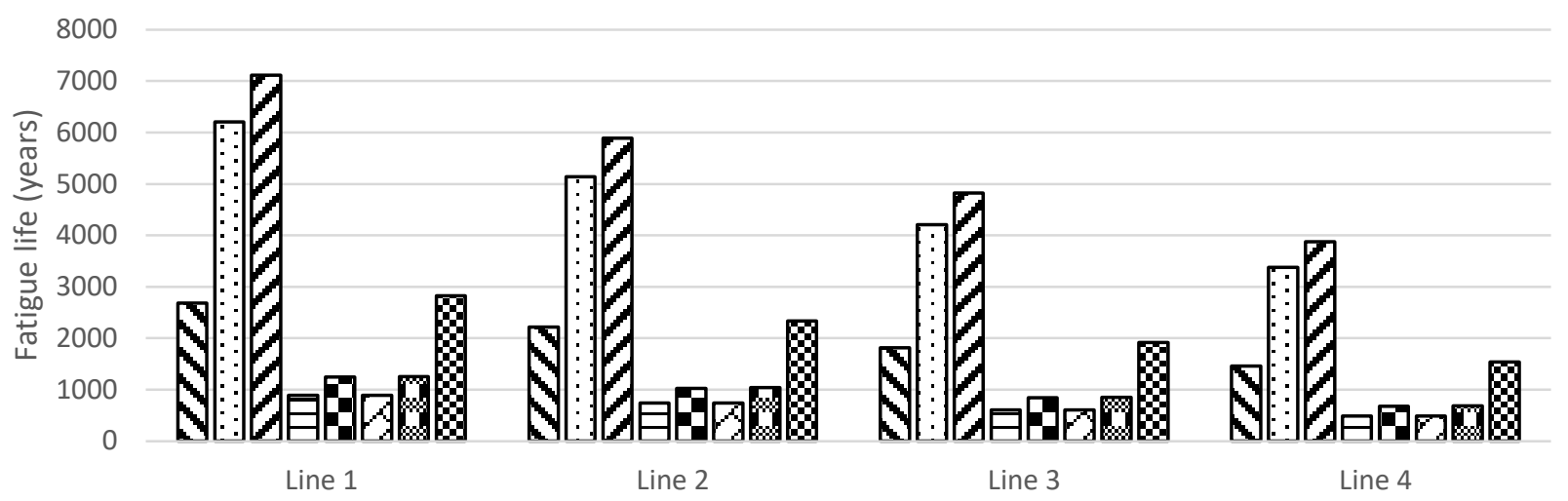

DT-N curves based approach (safety factor $=1.0$ ) $\square$ S-N curves based approach (safety factor $=1.0$ )

[d FM approach (weld section, SCF = 1.0)

日T-N curves based approach (safety factor $=3.0$ )

$\mathbf{\square}$ S-N curves based approach (safety factor $=5.0$ ) $\mathbf{Q F M}$ approach (weld section, SCF $=2.0$ )

a. FM approach (crown section)

由FM approach (bend section)

(a)

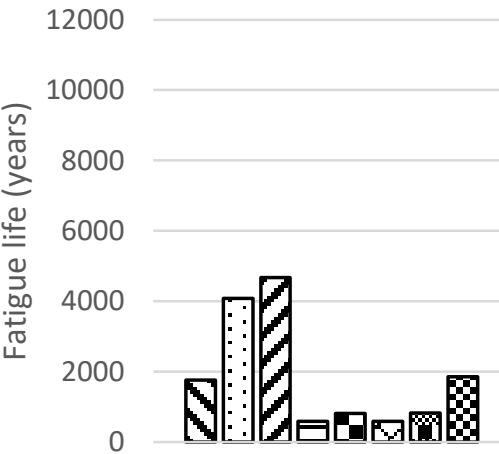

Line 5

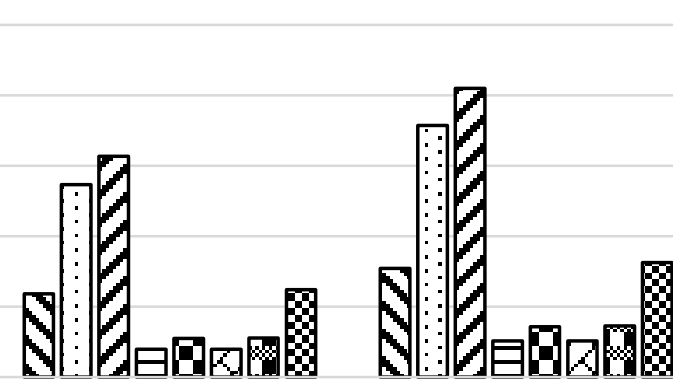

Line 7

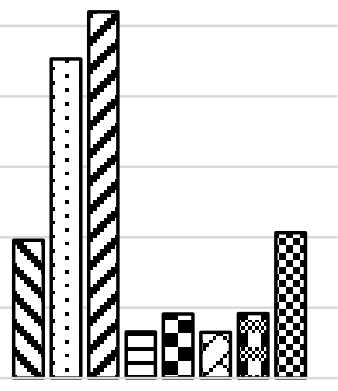

Line 8

$\boldsymbol{\nabla}$ T-N curves based approach (safety factor $=1.0$ ) $\mathbf{\square}$ S-N curves based approach (safety factor $=1.0$ )

DFM approach (weld section, SCF = 1.0)

日T-N curves based approach (safety factor $=3.0$ )

口 S-N curves based approach (safety factor $=5.0$ ) $\square$ FM approach (weld section, SCF $=2.0$ )

FM approach (crown section)

因FM approach (bend section)

(b) 


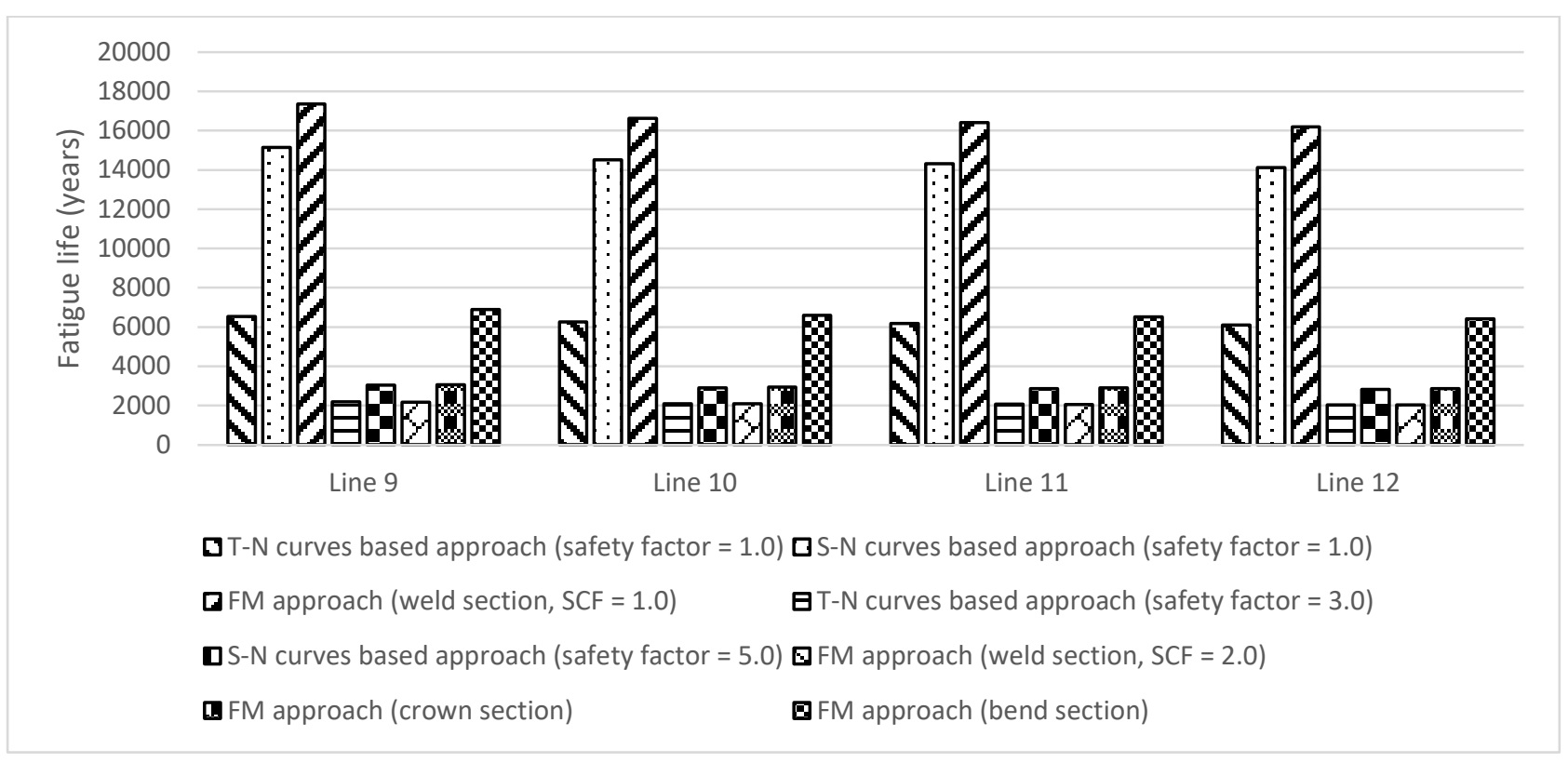

(c)

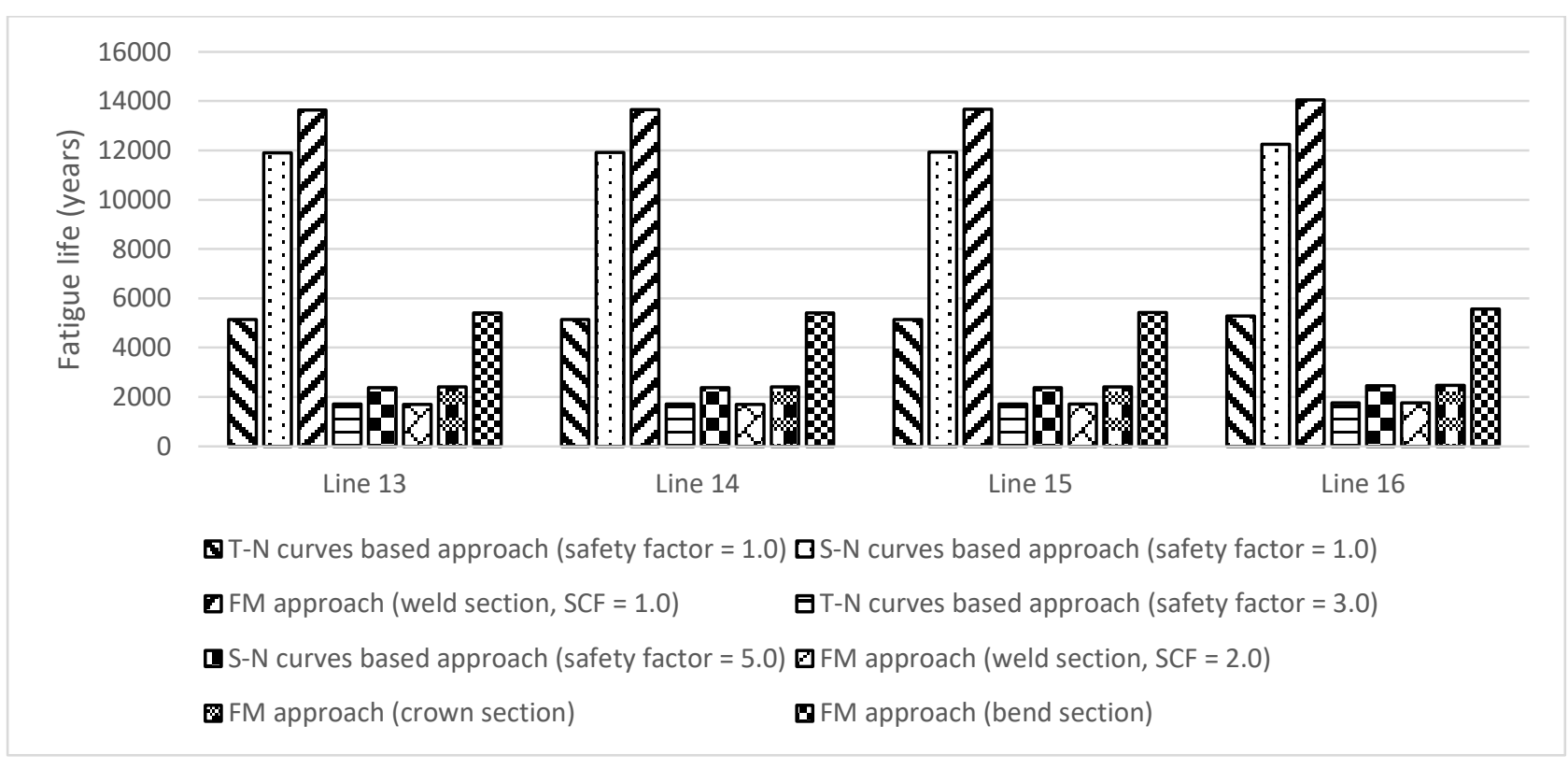

(d)

Fig. 15. T-N curves, S-N curves, and fracture mechanics based fatigue analyses for mooring chains subjected to the combined low frequency and wave frequency tension for Case C: (a) Line 1 to Line 4; (b) Line 5 to Line 8; (c) Line 9 to Line 12; (d) Line 13 to Line 16 


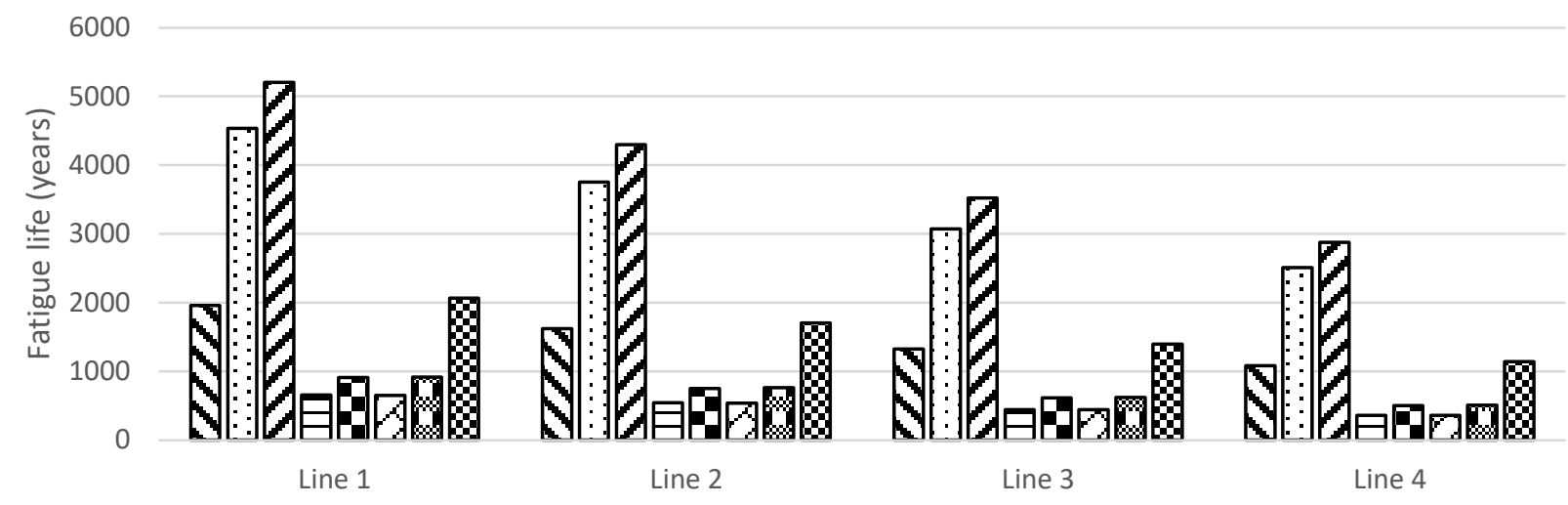

$\mathbf{Q}$ T-N curves based approach (safety factor $=1.0$ ) $\mathbf{\square}$ S-N curves based approach (safety factor $=1.0$ )

[ FM approach (weld section, SCF = 1.0)

田-N curves based approach (safety factor $=3.0$ )

Ⓢ-N curves based approach (safety factor = 5.0) 曰FM approach (weld section, SCF = 2.0)

- FM approach (crown section)

四M approach (bend section)

(a)

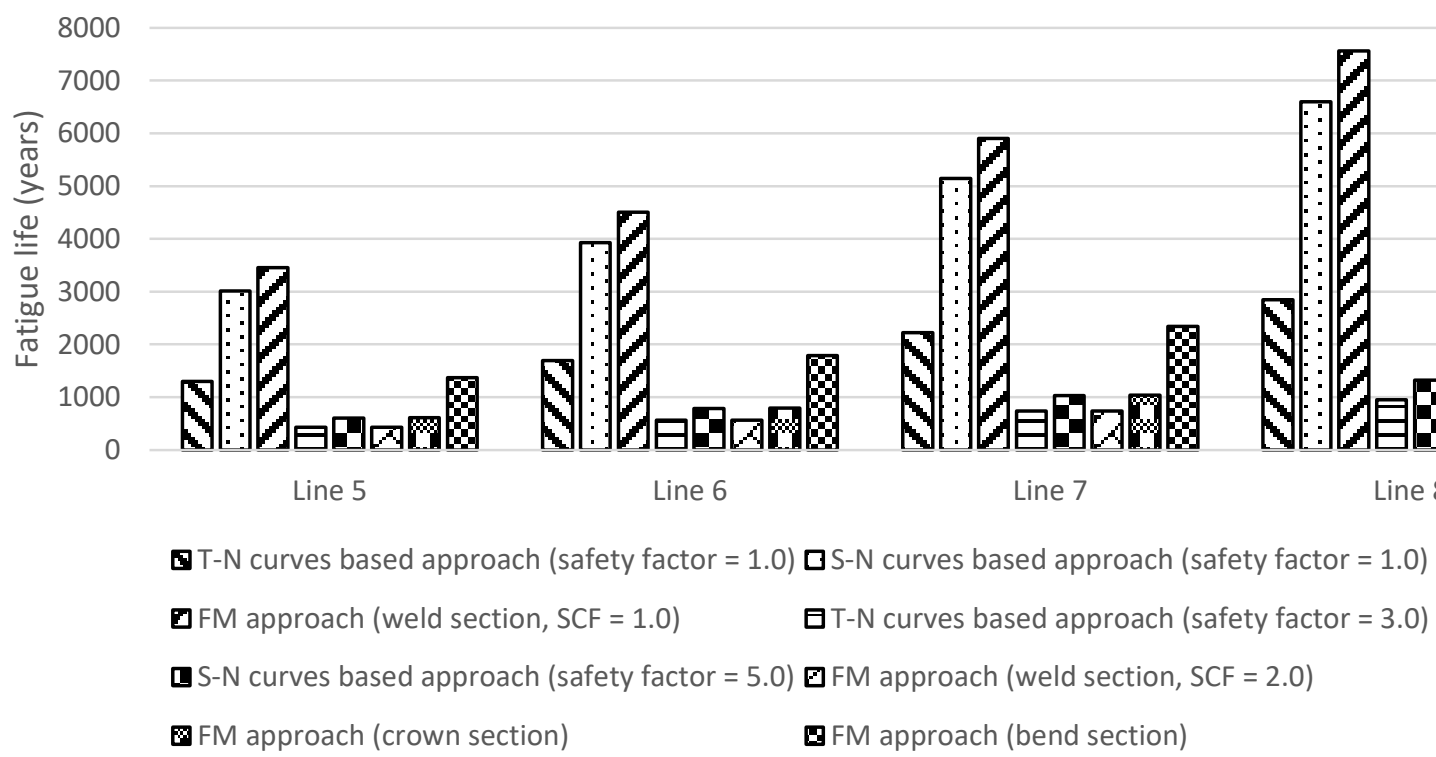

(b) 


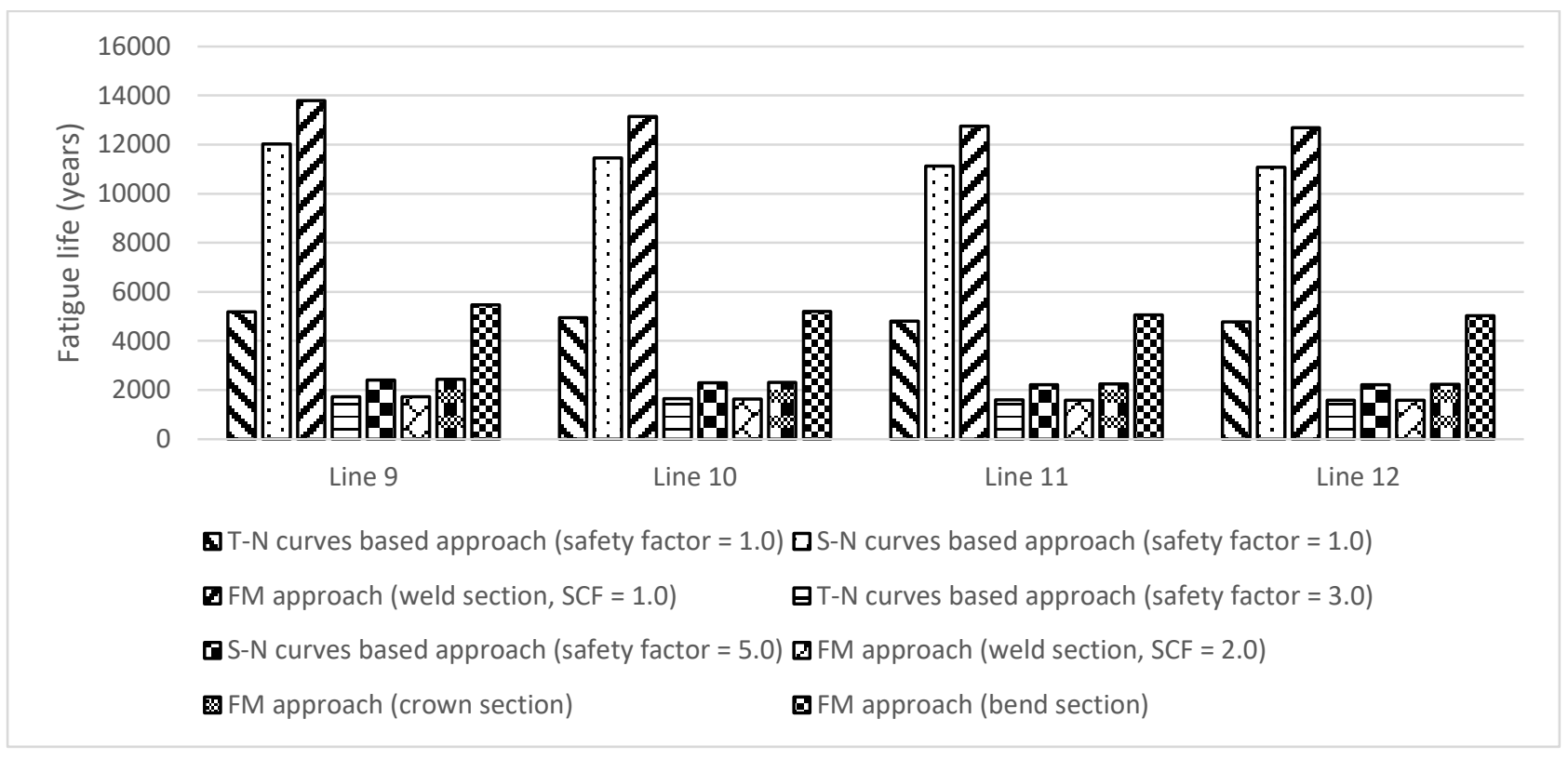

(c)

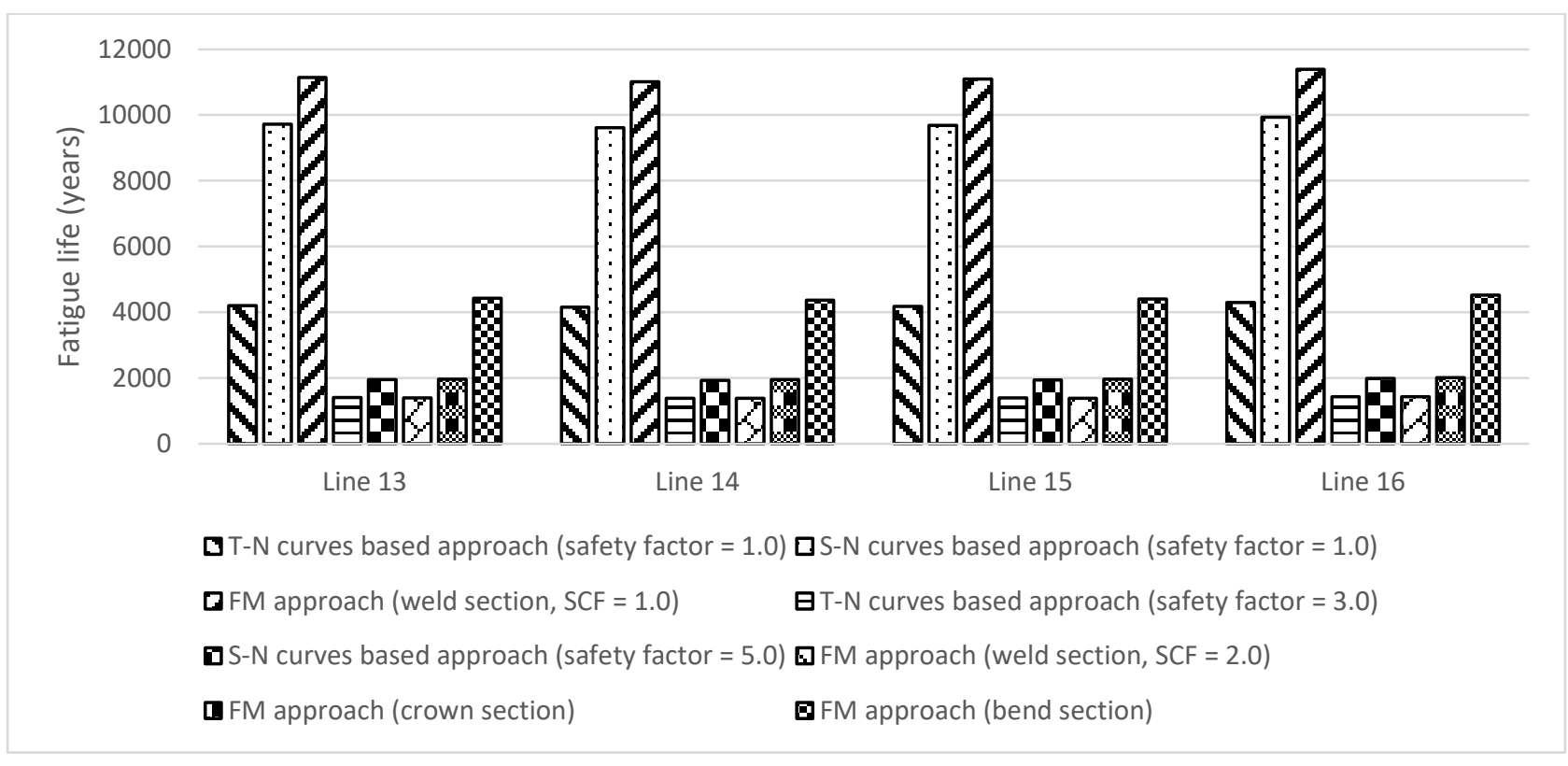

(d)

Fig. 16. T-N curves, S-N curves, and fracture mechanics based fatigue analyses for mooring chains subjected to the combined low frequency and wave frequency tension for Case D: (a) Line 1 to Line 4; (b) Line 5 to Line 8; (c) Line 9 to Line 12; (d) Line 13 to Line 16 


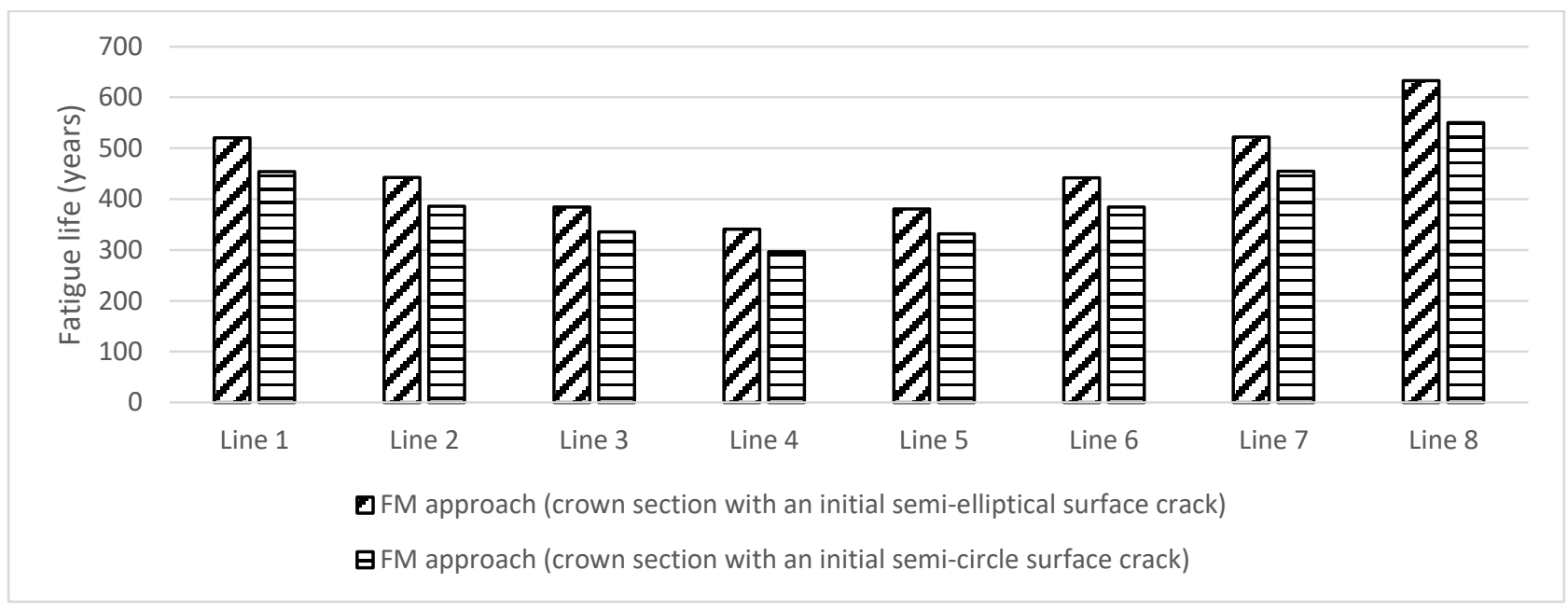

(a)

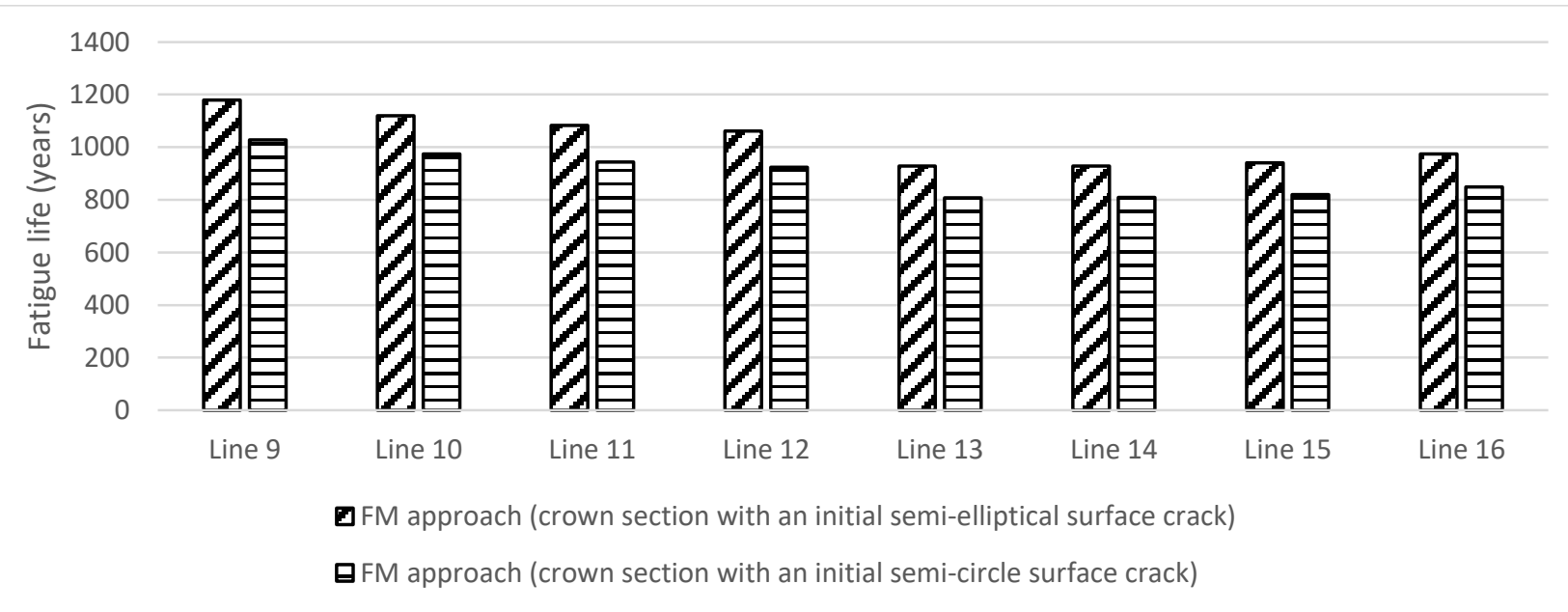

(b)

Fig. 17. Fracture mechanics based fatigue analyses for mooring chains with initial semi-elliptical surface cracks and initial semi-circle surface cracks for Case A: (a) Line 1 to Line 8; (b) Line 9 to Line 16 


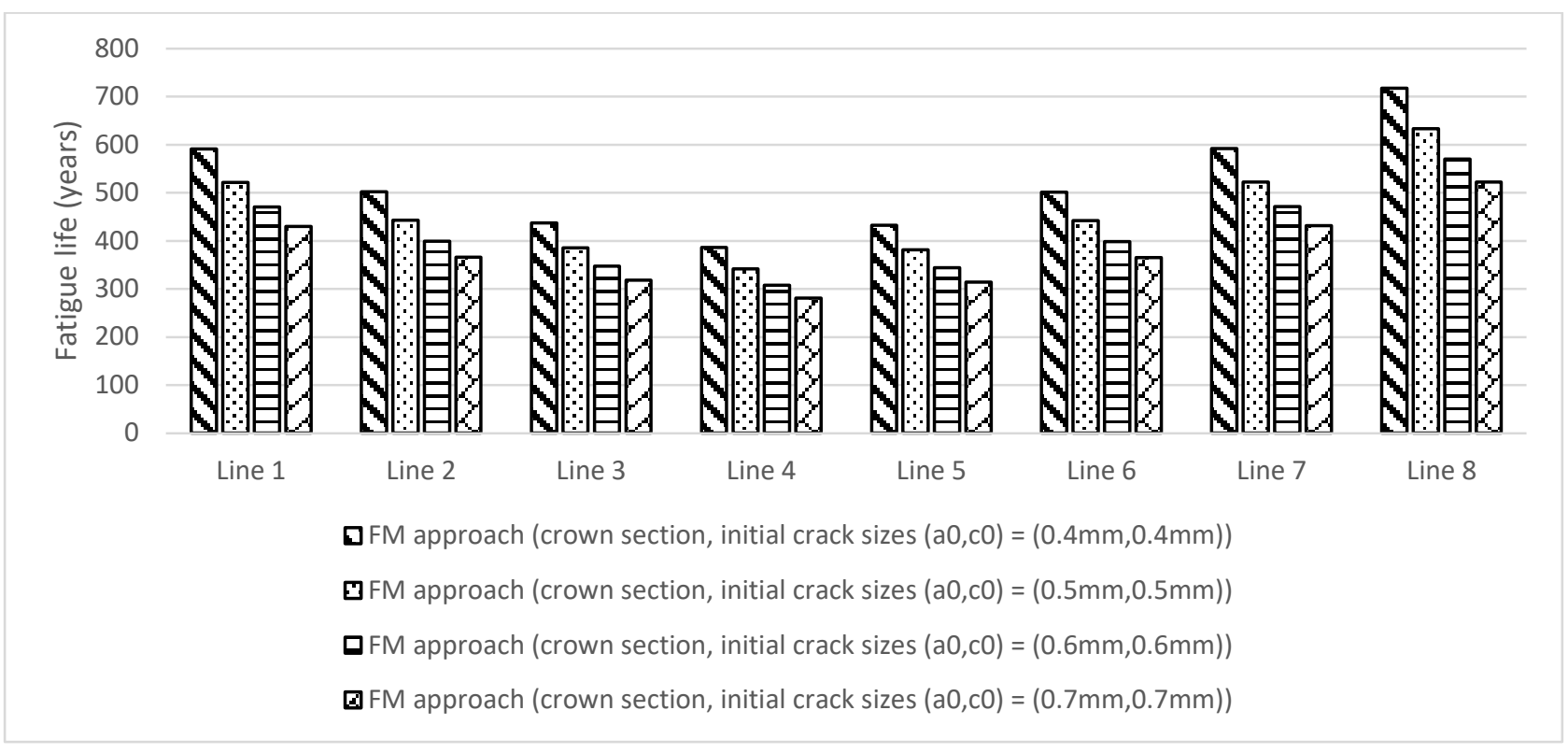

(a)

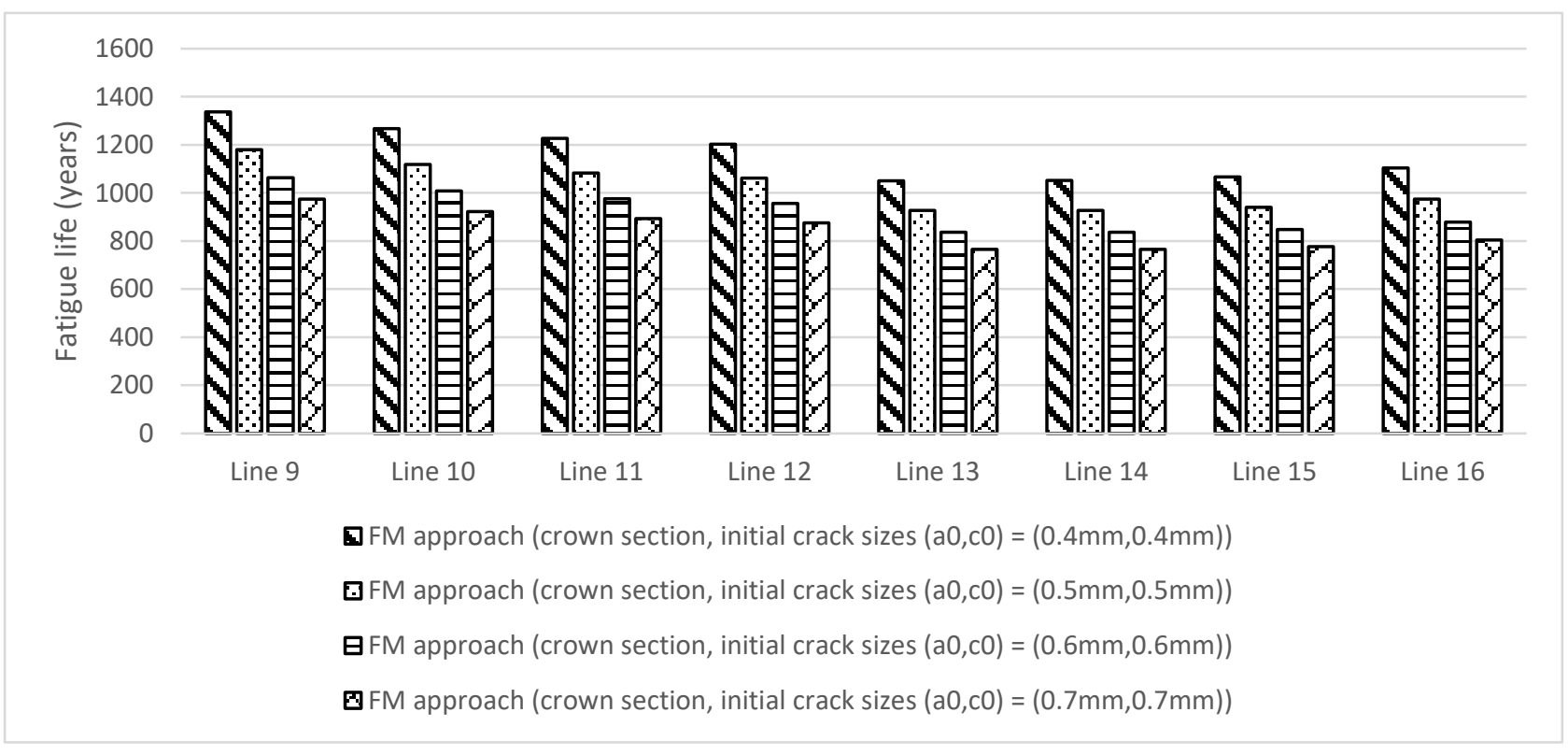

(b)

Fig. 18. Fracture mechanics based fatigue analyses for mooring chains with different initial crack sizes $\left(a_{0}, c_{0}\right)$ for Case A: (a) Line 1 to Line 8 ; $(b)$ Line 9 to Line 16 


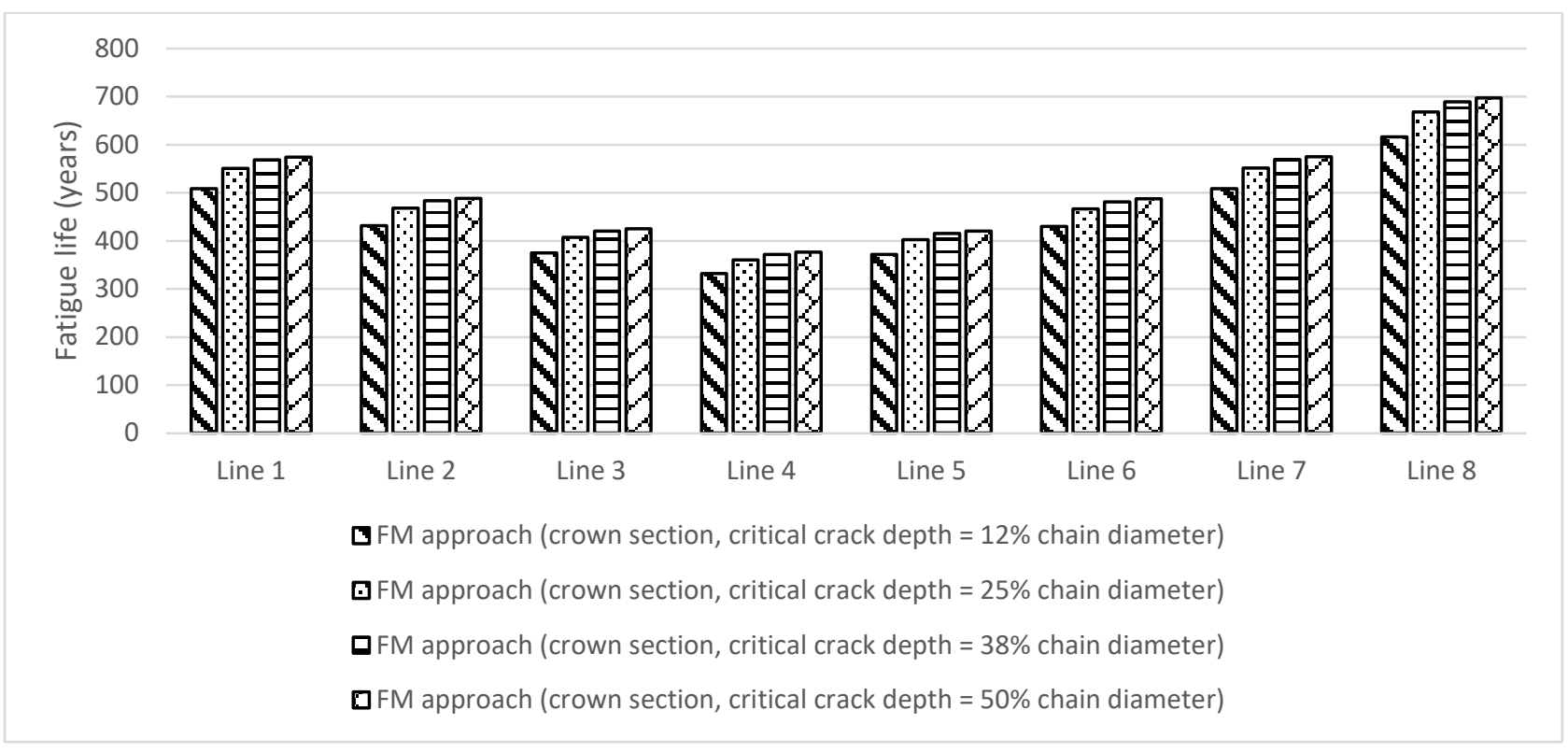

(a)

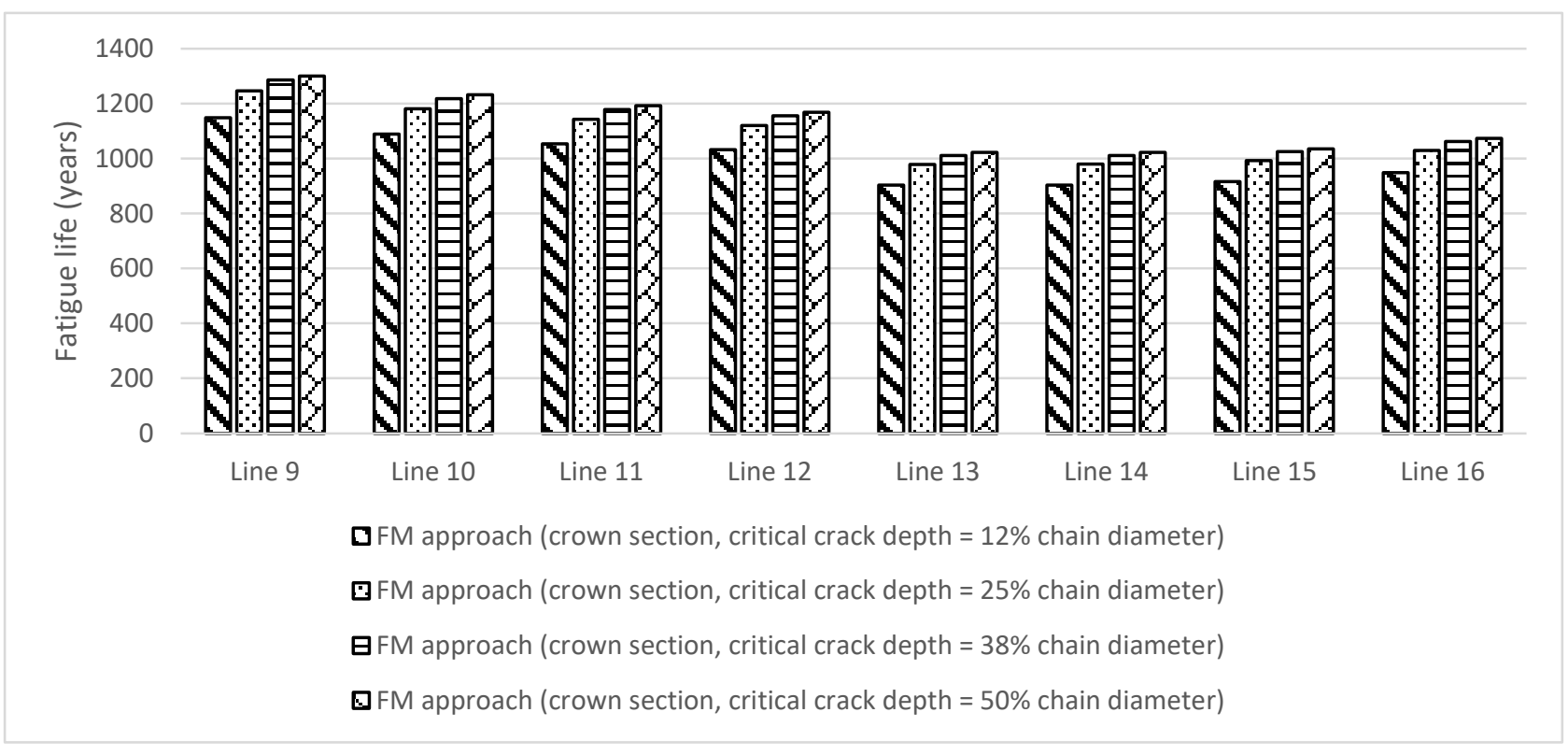

(b)

Fig. 19. Fracture mechanics based fatigue analyses for mooring chains with different critical crack depths for Case A: (a) Line 1 to Line 8; (b) Line 9 to Line 16 


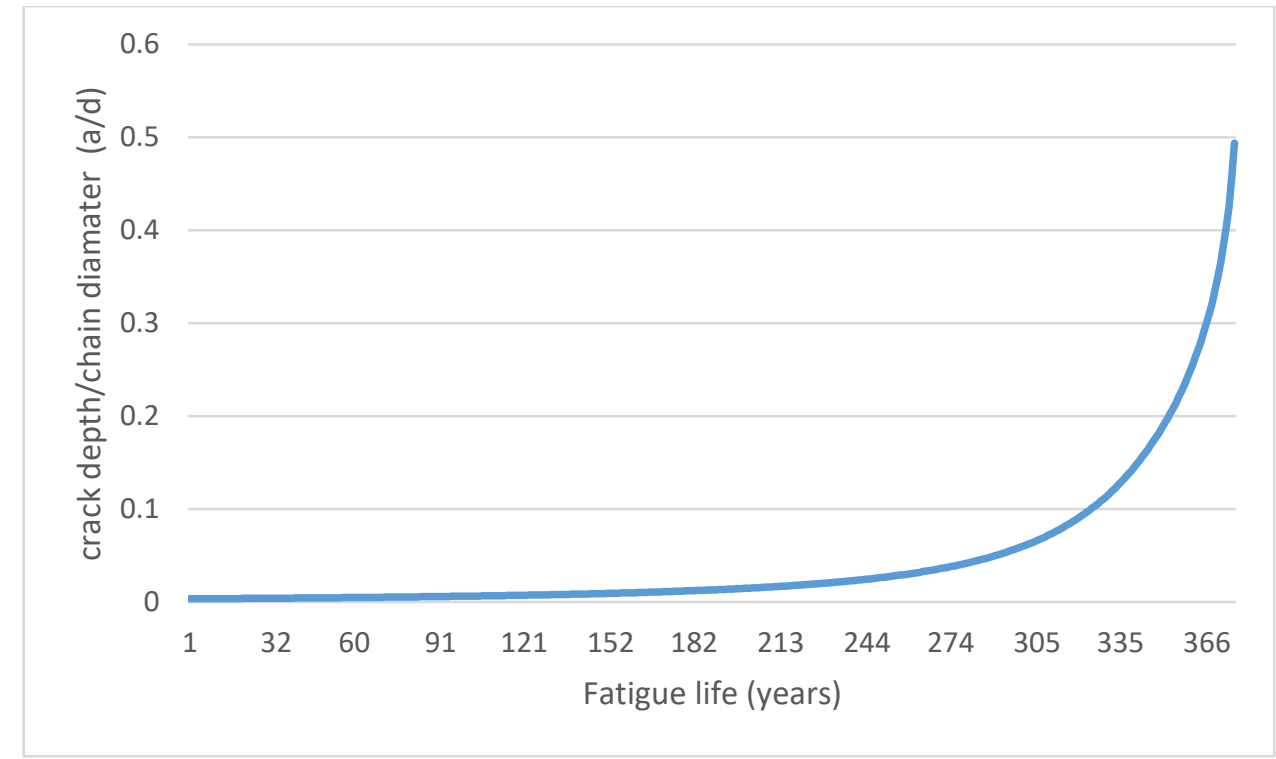

Fig. 20. Crack evolution of the crown section of mooring chain at the Line 4 fairlead in Case A 